This document is confidential and is proprietary to the American Chemical Society and its authors. Do not copy or disclose without written permission. If you have received this item in error, notify the sender and delete all copies.

\title{
Enhanced Generation of Reactive Species by Cold Plasma in Gelatin Solutions for Selective Cancer Therapy
}

\begin{tabular}{|r|l|}
\hline Journal: & ACS Applied Materials \& Interfaces \\
\hline Manuscript ID & Draft \\
\hline Manuscript Type: & Article \\
\hline Date Submitted by the & n/a \\
\hline Complete List of Authors: & $\begin{array}{l}\text { Labay, Cedric; Universitat Politecnica de Catalunya } \\
\text { Roldan, Marcel; Universitat Politecnica de Catalunya } \\
\text { Tampieri, Francesco; Universitat Politecnica de Catalunya, Department of } \\
\text { Materials Science and Metallurgy } \\
\text { Stacampiano, Augusto; GREMI } \\
\text { Escot Bocanegra, Pablo; GREMI } \\
\text { Ginebra, Maria-Pau; Universitat Politecnica de Catalunya, Department of } \\
\text { Materials Science and Metallurgical Engineering } \\
\text { Canal, Cristina; Universitat Politecnica de Catalunya, Materials Science } \\
\text { and Engineering Department }\end{array}$ \\
\hline
\end{tabular}

\section{SCHOLARONE Manuscripts}




\begin{abstract}
Atmospheric pressure plasma jets generate reactive oxygen and nitrogen species (RONS) in liquids and biological media, which find application in the new area of plasma medicine. These plasma-treated liquids demonstrated recently to possess selective properties on killing cancer cells and attract attention towards new plasma-based cancer therapies. These allow for local delivery by injection in the tumor but can be quickly washed away by body fluids. By confining these RONS in a suitable biocompatible delivery system, great perspectives can be opened in the design of novel biomaterials aimed for cancer therapies. Gelatin solutions are evaluated here to store RONS generated by atmospheric pressure plasma jets, and their release properties are evaluated. The concentration of RONS was studied in $2 \%$ gelatin as a function of different plasma parameters (treatment time, nozzle distance and gas flow) with two different plasma jets. Much higher production of reactive species $\left(\mathrm{H}_{2} \mathrm{O}_{2}\right.$ and $\left.\mathrm{NO}_{2}{ }^{-}\right)$was revealed in the polymer solution than in water after plasma treatment. The amount of RONS generated in gelatin is greatly improved with respect to water, with concentrations of $\mathrm{H}_{2} \mathrm{O}_{2}$ and $\mathrm{NO}_{2}{ }^{-}$between 2 and 12 times higher for the longest plasma treatments. Plasma-treated gelatin exhibited the release of these RONS to a liquid media, which induced an effective killing of bone cancer cells. Indeed, in vitro studies on Sarcoma Osteogenic (SaOS-2) cell line exposed to plasma-treated gelatin lead to timedependent increasing cytotoxicity with the longer plasma treatment time of gelatin. While SaOS2 cell viability decreased down to $12 \%-23 \%$ after 72 hours for cells exposed to 3-min treated gelatin, viability of healthy cells ( $\mathrm{hMSC}$ ) was preserved (around 90\%), establishing the selectivity of the plasma-treated gelatin on cancer cells. This sets the basis for designing improved hydrogels with high capacity to deliver RONS locally to tumors.
\end{abstract}

Keywords: Cold atmospheric plasma; hydrogel; osteosarcoma; reactive oxygen and nitrogen species. 


\section{INTRODUCTION}

The potential of targeting the oxidative stress response in cancer cells that could overcome drug resistance and spare normal tissue is being investigated as novel treatment by different techniques. Production of reactive oxygen and nitrogen species (RONS) in liquids (water, saline solutions, cell culture media) by treatment with cold atmospheric plasmas has been focus of interest in the last years due to its implications in biology and medicine (i.e. from wound healing to cancer treatment). Thus, the generation of species such as $\mathrm{H}_{2} \mathrm{O}_{2}, \mathrm{NO}_{2}^{-}, \mathrm{O}_{3}^{-}$or short-lived species has been extensively described ${ }^{1-4}$. The plasma-treated or plasma-conditioned liquids $(P C L)$ with biological effects provide a new window of opportunities for local treatment by injecting in the disease site. Taking advantage of the different basal levels of oxidative stress between healthy and cancer cell lines ${ }^{5-8}$, and the different sensitivity to reactive oxygen species (ROS), previous works demonstrated the selective effects of $P C L$ on killing cancer cells ${ }^{9-15}$. However, injection of PCL to the tumor may quickly be washed away by body fluids, so design of suitable biomaterials for delivery of these oxidative stress is of paramount importance. In this sense, and to also foster higher concentrations of RONS in suitable biocompatible vehicles studies on PCL were broadened to alginate solutions, that proved to be good candidates to enhance generation of RONS ${ }^{16}$. Therefore, developing vehicles of these RONS for enhanced local delivery to the diseased site would be a very interesting asset.

Gelatin is a translucid and thermosensitive hydrogel derived from collagen. Since collagen is the most abundant extracellular matrix protein in humans and animals, and the main component of connective tissues (such as skin, ligament, tendons, etc.), gelatin presents a high biocompatibility, making it a great candidate to be used in the design of hydrogel-based implantable biomaterials. Indeed, as biomaterials for tissue engineering, a wide diversity of gelatin-based structures have been described in literature ${ }^{17}$ including nano- and microspheres $^{18,19}$ or particles, 3D scaffolds ${ }^{20-24}$, electrospun nanofibers ${ }^{25-27}$, cryogel scaffolds ${ }^{28}$, composite materials ${ }^{29-31}$ and in situ gelling formulations. This reverts in a broad range of applications going from drug and growth factors delivery ${ }^{18,19,30}$ to tissue repair and regeneration for ocular ${ }^{23}$, bone ${ }^{30}$, skeletal muscle ${ }^{32}$ or soft tissue ${ }^{24,31}$ engineering.

The first studies involving cold atmospheric plasma treatment of gelled gelatin used it as a surrogate of human tissues - i.e. skin - to study its barrier effects on incoming RONS generated by different kinds of plasma treatment (plasma jet, barrier discharge). The penetration of RONS through gelatin gel films was quantified measuring the concentrations in the water underneath such films ${ }^{33-35}$. Other materials such as agarose ${ }^{36}$ and phospholipid membranes ${ }^{37}$ were employed to model living tissues, where the authors also focused on the transport and diffusion of the RONS through these layers.

Here, we intend to describe for the first time the ability of gelatin solutions to successfully increase, store and deliver reactive species generated by cold atmospheric plasmas with the purpose to further include the plasma-treated biopolymer in the design of hydrogel-based biomaterial acting as vehicles of RONS for cancer therapy. A wide variety of plasma jets have been described, producing different biological effects, so here focus will be put on comparing a helium atmospheric pressure plasma jet (APPJ) to a standard commercial source argon jet (known as kINPen) on the production of RONS in gelatin and investigating its potential biological effects. 


\section{EXPERIMENTAL SECTION}

\subsection{Materials}

Gelatin type B (Rousselot 250 LB8, Rousselot, France), in powder form and MilliQ water (MilliPore, Merck) (designated here as DI water) were used for preparation of biopolymer solution. Argon (Ar 5.0) and Helium (He 5.0) employed as precursor gas to generate plasma (PRAXAIR, Spain).

Sulfanilamide (Sigma-Aldrich, USA), N-(1-naphthyl)ethylenediamine dihydrochloride (SigmaAldrich, USA) and ortho-phosphoric acid $85 \%$, pure, pharma grade $\left(\mathrm{H}_{3} \mathrm{PO}_{4}\right)(85 \%)$ (Panreac, USA) have been used for the preparation of Griess reagent, used for $\mathrm{NO}_{2}{ }^{-}$detection. Sodium nitrite $\left(\mathrm{NaNO}_{2}\right.$, Sigma-Aldrich, USA) used for calibration curves of nitrites. Sodium azide $\left(\mathrm{NaN}_{3}\right)$, Titanium(IV) oxysulfate-sulfuric acid solution $\left(\mathrm{TiOSO}_{4}\right)$ and $30 \%(\mathrm{w} / \mathrm{w})$ hydrogen peroxide $\left(\mathrm{H}_{2} \mathrm{O}_{2}\right)$ solution used for detection of hydrogen peroxides in water were purchased from Sigma Aldrich. Amplex ${ }^{\mathrm{TM}}$ Red reagent (Invitrogen ${ }^{\mathrm{TM}}$, Thermo Fisher Scientific) and peroxidase from horseradish (Type VI) (HRP) (Sigma-Aldrich, USA) were used for determination of $\mathrm{H}_{2} \mathrm{O}_{2}$ in gelatin.

Nunclon ${ }^{\mathrm{TM}}$ Delta Surface 24-well and 96-well plates (ThermoFisher Scientific) and Corning ${ }^{\circledR}$ Transwell ${ }^{\circledR}$ polyester membrane cell culture inserts $6.5 \mathrm{~mm}$ Transwell ${ }^{\circledR}$ with $0.4 \mu \mathrm{m}$ pore polyester membrane insert, TC-treated, sterile (Corning, Inc., USA) were used for in vitro cell experiments. Sarcoma osteogenic SaOS-2 (HTB-85, \#70014245, ATCC, USA) were cultured in Mc Coy's 5A medium (modified, with sodium bicarbonate, without L-glutamine, liquid, sterilefiltered, suitable for cell culture), purchased from Sigma Aldrich. Bone marrow-derived Mesenchymal Stem Cells hMSC (PCS-500-012, \#70014245, ATCC, USA) were cultured in Advanced Dulbecco's Eagle Medium (1X) (AdvDMEM) (Gibco, ThermoFisher Scientific). To supplement cell culture media, Foetal Bovine Serum (FBS), Penicillin/Streptomycin (P/S) and Trypsin were purchased from ThermoFisher Scientific. Dulbecco's Phosphate Buffered Saline (PBS) used for in vitro cell assay and release experiments were obtained from Biowest (Biowest SAS, France). For sample preparation for confocal microscopy, Tween 20 (Sigma-Aldrich), SuperBlock ${ }^{\text {TM }}$ (TBS) (ThermoScientific, Ref. 37535, USA) Alexa Fluor ${ }^{\circledast} 546$ Phalloidin (Invitrogen ${ }^{\mathrm{TM}}$ ), ProLong ${ }^{\circledR}$ Gold antifade with DAPI (Invitrogen ${ }^{\mathrm{TM}}, \mathrm{P} 36931$, USA) were used.

\subsection{Preparation of gelatin solution}

Gelatin in powder form was mixed with MilliQ water at $37{ }^{\circ} \mathrm{C}$ using magnetic stirring for 2 hours to obtain a $2 \%{ }_{w t / w t}$ gelatin solution. $2 \%$ gelatin solution was stored at $4{ }^{\circ} \mathrm{C}$ and brought to $37^{\circ} \mathrm{C}$ before plasma treatment.

\subsection{Plasma treatment}

In his work, two plasma sources were employed: an APPJ, using helium as plasma gas and whose design is based on a single electrode as described in literature ${ }^{38}$ and a commercial kINPen ${ }^{\circledR}$ IND (NEOPLAS Tools, Germany) ${ }^{39}$ operating with argon. Plasma treatment times up to 5 minutes were performed to either water or gelatin solutions. Nozzle distance to the solution surface was tested from $10 \mathrm{~mm}$ to $20 \mathrm{~mm}$. Gas flow, controlled by Ar and He Bronkhorst Mass View flow controllers (Bronkhorst ${ }^{\circledR}$, Netherlands), was employed between 1 and $5 \mathrm{~L} / \mathrm{min}$ for APPJ and 1 and $2.5 \mathrm{~L} / \mathrm{min}$ for kINPen due to the different configurations of the two plasma jets. To evaluate 
the effects of APPJ and kINPen plasma treatment conditions on the amount of RONS generated in gelatin solution and the ageing of RONS, $200 \mu \mathrm{L}$ of $2 \%$ gelatin solution previously warmed at $37^{\circ} \mathrm{C}$ were put for treatment in a 96-well plate on a dielectric plate at floating potential Error! Reference source not found.(ungrounded samples). MilliQ water has been used as control in the same conditions.

\section{4. $\mathrm{pH}$ monitoring}

$2 \mathrm{~mL}$ of $2 \%$ gelatin solution brought to $37^{\circ} \mathrm{C}$ were put in 24-well plates and treated with APPJ or kINPen at $10 \mathrm{~mm}$ nozzle distance and $1 \mathrm{~L} / \mathrm{min}$ gas flow. Evolution of the $\mathrm{pH}$ as a function of plasma treatment time was measured by using a PC80 Multiparameter instrument (XS Instruments, Italy) with a Crison 5014 electrode (Crison, Spain).

\subsection{Infrared imaging of plasma-treated gelatin solution}

Non-invasive temperature measurements were effectuated by means of an infrared camera (Fluke Ti480 by Fluke) with resolution of $640 \times 640$ pixels and an accuracy of $\pm 2{ }^{\circ} \mathrm{C}$. An initial calibration of the camera acquisition was effectuated using a standard thermocouple to measure the target temperature by contact. The emissivity was corrected with the calibration procedure. The camera was mounted $15 \mathrm{~cm}$ above the sample and focused on the sample surface. The acquisitions are reported on a scale from 10 to $40{ }^{\circ} \mathrm{C}$ so to accentuate the temperature gradients.

\subsection{Detection of RONS}

Quantification of plasma generated $\mathrm{NO}_{2}^{-}$in $2 \%$ of gelatin solutions and in DI water was performed by Griess test ${ }^{1,4,40,41}$. Griess reagent (GR) was prepared by dissolution of $0.1 \% \mathrm{wt} / \mathrm{v}$ of $\mathrm{N}$-(1-naphthyl) ethylenediamine dihydrochloride, $1 \% \mathrm{wt} / \mathrm{v}$ of sulphanilamide, and $5 \% \mathrm{wt} / \mathrm{v}$ of phosphoric acid in DI water. $200 \mu \mathrm{L}$ of GR were added on the $200 \mu \mathrm{L}$ of plasma-treated sample in a 96-well plate (Figure 2a). Incubation of the plate protected from light was done for $10 \mathrm{~min}$ at room temperature before absorbance measurement at $\lambda=540 \mathrm{~nm}$ using a Synergy HTX Hybrid Multi Mode Microplate Reader (BioTek Instruments, Inc., USA). Calibration curves to correlate absorbance with concentration were made from $\mathrm{NaNO}_{2}$ standard solutions with proper dilutions.

Quantification of plasma generated $\mathrm{H}_{2} \mathrm{O}_{2}$ in $2 \%$ gelatin solution or in water was performed by fluorescence measurement from the conversion of $\mathrm{H}_{2} \mathrm{O}_{2}$ in resorufin (fluorescent product) using $100 \mu \mathrm{M}$ Amplex ${ }^{\mathrm{TM}}$ Red reagent with $0.25 \mathrm{U} / \mathrm{mL} \mathrm{HRP}$ as catalyst. The plasma-treated $2 \%$ gelatin solution samples were diluted 1:200 to proceed to the detection of $\mathrm{H}_{2} \mathrm{O}_{2}$ within the linear concentration range. $50 \mu \mathrm{L}$ of the reagent were added to $200 \mu \mathrm{L}$ of the diluted samples in a 96well plate and that was incubated at $37{ }^{\circ} \mathrm{C}$ for $30 \mathrm{~min}$. Fluorescence measurements were performed using a Synergy ${ }^{\text {TM }}$ HTX Multi-Mode Microplate Reader (Biotek, USA) using 560/20 nm and 590/20 $\mathrm{nm}$ as filters for excitation and emission wavelengths, respectively. 


\subsection{Stability of RONS}

The time stability of $\mathrm{H}_{2} \mathrm{O}_{2}$ and $\mathrm{NO}_{2}{ }^{-}$after storage of the plasma-treated $2 \%$ gelatin solution was measured following the protocol previously described, for each of the species. Gelatin solutions was stored either at $4{ }^{\circ} \mathrm{C}$ or $37^{\circ} \mathrm{C}$. DI water was used as control.

\subsection{Release of RONS from plasma-treated hydrogels}

$200 \mu \mathrm{L}$ of $2 \%$ gelatin solution were treated by APPJ or kINPen in $96-$ well plate at $10 \mathrm{~mm}$ with gas flow rate of $1 \mathrm{~L} / \mathrm{min}$ during 30,90 and $180 \mathrm{~s}$. Then, plasma-treated gelatin samples, together with untreated gelatin as control, were transferred into Corning ${ }^{\circledR}$ Transwell ${ }^{\circledast}$ cell culture inserts and placed in $1 \mathrm{~mL}$ of PBS used as release medium in 24-well plates. Release kinetics of RONS from the gelatin to the PBS were plotted from withdrawals of $100 \mu \mathrm{L}$ of the release medium at determined time points. $50 \mu \mathrm{L}$ were used for $\mathrm{NO}_{2}{ }^{-}$and $50 \mu \mathrm{L}$ for $\mathrm{H}_{2} \mathrm{O}_{2}$ detection, following the same experimental protocol described for RONS detection in DI water. $100 \mu \mathrm{L}$ of fresh PBS at 37 ${ }^{\circ} \mathrm{C}$ were replaced after each sample withdrawal. At the end of the release experiments, final volumes of the release media were measured to consider any water evaporation. Thus, two volume corrections were taken into account to determine precisely the concentration RONS in the release medium at each moment $t$ : (i) a step to step correction due to sample withdrawal and (ii) a total volume correction due to evaporation. Gelatine solutions were treated by plasma immediately before starting the RONS release experiments (without any storage time).

\subsection{In vitro cell experiments}

Sarcoma osteogenic SaOS-2 cells were used to evaluate the cytotoxicity of the plasma-treated $2 \%$ gelatin solutions on cancer cells. Cell culture medium of SaOS-2 consisted of Mc Coy's $5 \mathrm{~A}$ medium supplemented with $10 \% \mathrm{FBS}$ and $1 \% \mathrm{P} / \mathrm{S}$. Subconfluent SaOS-2 were detached from the flask using trypsin, centrifuged and seeded with a density of 10000 cells/well in 24-well plates with $1 \mathrm{~mL}$ volume of complete cell culture medium. After 6 -hour adhesion, plasma-treated $2 \%$ gelatin solution samples were transferred to Transwell ${ }^{\circledR}$ inserts and placed in the wells. Gelatin solution used for cell experiments was previously heated at $37^{\circ} \mathrm{C}$ and filtered with $0.22 \mu \mathrm{m}$ diameter pore Millex-GP filters (Millipore, Merck) before plasma treatment. Plasma treatments of the $2 \%$ gelatin solution used for in vitro cell experiments were performed with APPJ or kINPen for 30,90 and $180 \mathrm{~s}$ using a $10 \mathrm{~mm}$ nozzle distance and $1 \mathrm{~L} / \mathrm{min}$ gas flow rate. The same density of cells was seeded in the same conditions in empty well (cell only) and in presence of untreated gelatin, as controls. The cells were grown at $37^{\circ} \mathrm{C}$ for another 24 and 72 hours.

Bone marrow-derived Mesenchymal Stem Cells (hMSC) were used to evaluate the selectivity of plasma-treated gelatin between cancer and healthy cell lines. Cell culture medium of hMSC consisted of AdvDMEM supplemented with $10 \%$ FBS and 1\% P/S. Seeding, cell density and experimental design of hMSC were reproduced in the exact same conditions such as presented above with SaOS-2. hMSC cell viability was evaluated at 72 hours for cells in presence of untreated gelatin (control), APPJ- or kINPen-treated $2 \%$ gelatin solutions for the longest plasma treatment studied (180 s). 
Cell viability at 24 and 72 hours was evaluated with WST-1 reagent following supplier's protocol. Absorbance was measured at $\lambda_{\mathrm{abs}}=440 \mathrm{~nm}$ using a Synergy HTX Hybrid Multi Mode Microplate Reader (BioTek Instruments, Inc., USA). Normalization of the absorbance values was made with respect to cells only to determine the effects of untreated and plasma-treated $2 \%$ gelatin solution on SaOS-2 cell viability. Cell viability was also assessed by imaging the well plates by optical microscopy to check the coherence of the results.

\subsection{Confocal Laser Scanning Microscopy}

SaOS-2 cells were seeded on round glass slides in the bottom of a 24-well plate with a density of 3.0x $10^{4}$ cells per well in $1 \mathrm{~mL}$ of McCoy's $5 \mathrm{~A}$ medium supplemented with $10 \% \mathrm{FBS}$ and $1 \% \mathrm{P} / \mathrm{S}$. After 6-hour adhesion, plasma-treated gelatin samples were transferred to Transwell ${ }^{\circledR}$ inserts and placed in the wells. The same density of cells was seeded in the same conditions without adding gelatin, as positive control. After 48 hours, SaOS-2 cells were fixed with $4 \%$ paraformaldehyde (PFA)/DPBS for $30 \mathrm{~min}$ at room temperature, $3 x$ washed with PBS, and permeabilized with $0.1 \%$ Tween20/PBS during $30 \mathrm{~min}$. They were washed three times with PBS and non-specifically points were blocked using SuperBlock ${ }^{\mathrm{TM}}$ (TBS) for $2 \mathrm{~h}$. Then, cells were $3 \mathrm{x}$ washed and actin filaments were labelled using Alexa Fluor ${ }^{\circledR} 546$ Phalloidin (AF546)/PBS in a dilution 1:300 to discern the cytoskeleton. After 1-hour incubation, samples were washed three times with PBS, and mounted using ProLong ${ }^{\circledR}$ Gold antifade with DAPI, allowing nuclei staining. SaOS-2 cells were imaged with a Zeiss LSM 800 Confocal Laser Scanning Microscope (CLSM) and processed with ZEN 2.3 software (Zeiss, Germany). Immunofluorescence images were taken using a 40x oil objective, using $557 \mathrm{~nm}$ and $353 \mathrm{~nm}$ as excitation wavelengths and 560-700 nm and 400-555 $\mathrm{nm}$ as detection wavelengths for AF546 and DAPI, respectively.

\subsection{Data analysis}

Statistical differences were determined using one-way ANOVA a 95\% confidence with Tukey's post-tests using Minitab 19 software (Minitab, Inc., State College, PA). Statistical significance was noted when $p<0.05$. 


\subsection{Thermal effects of cold atmospheric plasma treatment}

(a)
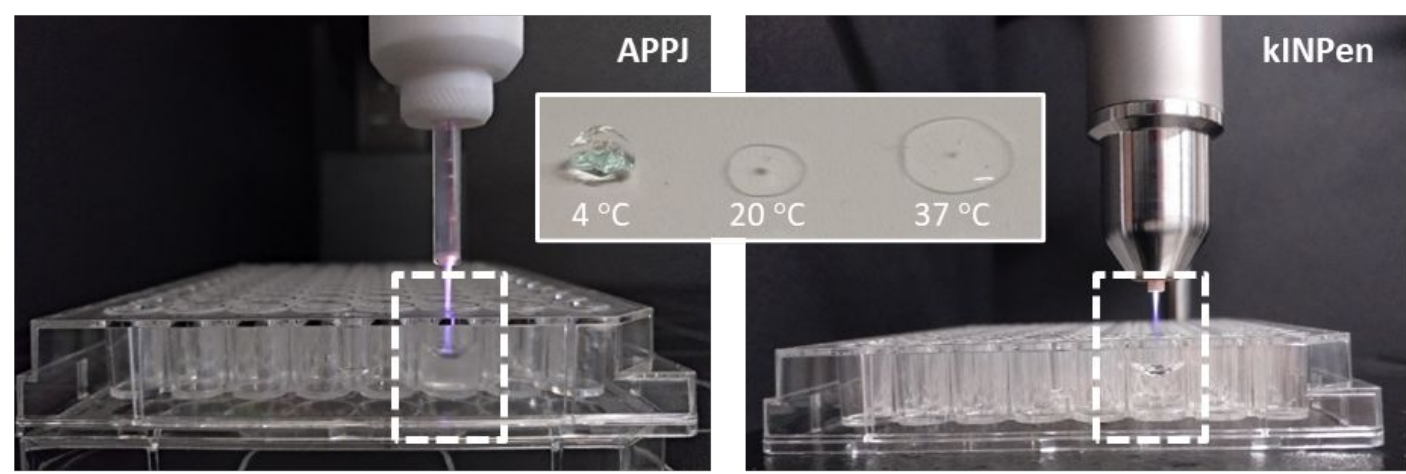

(b)

APPJ (He)
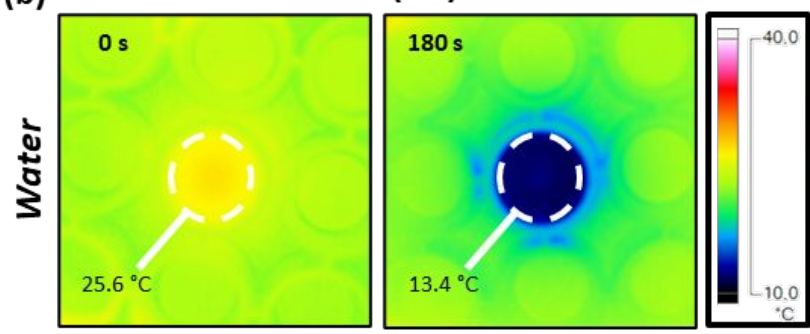

kINPen (Ar)


Figure 1: Configuration of the plasma treatment of gelatin using an APPJ and kINPen (a) together with the physical aspect of gelatin as function of temperature (inset). Thermal effects after $180 \mathrm{~s}$ of plasma treatment of water or $2 \%$ gelatin solution using APPJ and kINPen $(10 \mathrm{~mm}, 1 \mathrm{~L} / \mathrm{min})$ monitored by infrared camera. The temperature value is calculated as an average over the gelatine surface (b).

Plasma treatments of $200 \mu \mathrm{L}$ gelatin solution and water have been performed using APPJ and kINPen. The temperature of the solution was measured by IR imaging before and after plasma treatment and comparative results are presented in Figure 1. While both water and gelatin remain around the initial temperature after $180 \mathrm{~s}$ plasma treatment for kINPen device, plasma treatment using APPJ induces cooling for both samples, with a decrease of $11{ }^{\circ} \mathrm{C}$ and $12{ }^{\circ} \mathrm{C}$ for gelatin and water, respectively. To study the contributions of the gas flow on the thermal effects caused on water and gelatin, controls with only gas flow were performed (Supplementary Figure 1). Both devices are fed with high purity dry gas ( $\mathrm{Ar}$ or $\mathrm{He}$ ) which induces strong evaporation from the gelatin/water free surface. The thermal energy lost to evaporation induces a cooling of the sample as confirmed by only gas tests. Assuming the enthalpy of water vaporization in gelatin solution is the same as in pure water $(2257 \mathrm{~J} / \mathrm{g})$, an evaporation of $100 \mu \mathrm{L}$ over $180 \mathrm{~s}$ 
results in a cooling power of approximately $1.25 \mathrm{~W}$. On the other side, a portion of the total power consumed by the plasma sources $(2.1 \mathrm{~W}$ for APPJ and $8.4 \mathrm{~W}$ for kINPen on the gelatin solution) is delivered to the target as heat through Joule effect or electromagnetic emission. While for APPJ the cooling effect is stronger than the heating one, for kINPen they are comparable. Both plasma devices warm the samples, but in the case of kINPen, the warming effect is sufficient to counterbalance the cooling effect of evaporation. This can be attributed to the different powers of the two sources.

\subsection{Influence of plasma treatment on the generation of RONS in gelatin}

Figure $2 b$ \& $c$ show the concentration of $\mathrm{NO}_{2}{ }^{-}$and $\mathrm{H}_{2} \mathrm{O}_{2}$ generated in $2 \%$ gelatin solution or distilled water as a function of the plasma treatment time, using APPJ or kINPen. Higher amount of $\mathrm{NO}_{2}^{-}$and $\mathrm{H}_{2} \mathrm{O}_{2}$ was measured in $2 \%$ gelatin solution compared with water for any of the conditions studied. In both cases of hydrogel or water, production of RONS increases with the plasma treatment time. In DI water, $\mathrm{NO}_{2}{ }^{-}$concentration does not further increase after 2-min plasma treatment. Furthermore, production of RONS by kINPen is always higher than using APPJ in $2 \%$ gelatin solution and it is equal or higher for water, for similar plasma treatment times. 
(a)
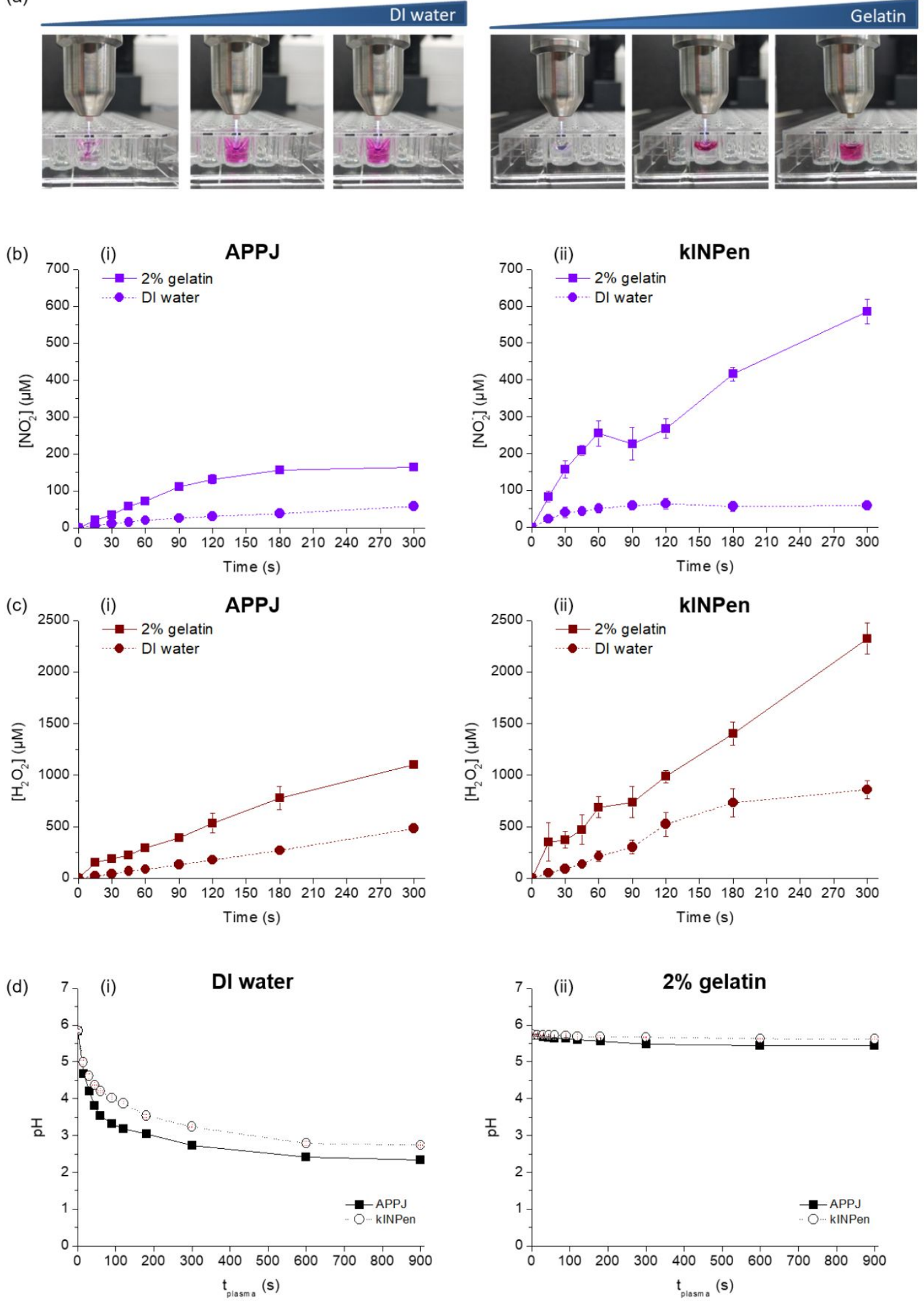

Figure 2. Plasma treatment of distilled water and $2 \%$ gelatin solution in presence of Griess reagent for $\mathrm{NO}_{2}{ }^{-}$detection (a). Influence of plasma treatment time on $\mathrm{NO}_{2}^{-}$(b) and $\mathrm{H}_{2} \mathrm{O}_{2}$ (c) generation in APPJ- (i) and kINPen-treated (ii) $2 \%$ gelatin solution for $10 \mathrm{~mm}$ nozzle distance to the liquid surface and $1 \mathrm{~L} / \mathrm{min}$ gas flow rate, together with the controls in DI water. Monitoring of the $\mathrm{pH}$ of $2 \%$ gelatin and DI water in the same conditions (d). 
The $\mathrm{pH}$ of water decreases quickly at short plasma treatment times to below 3 after $900 \mathrm{~s}$ of treatment, while the $\mathrm{pH}$ of $2 \%$ gelatin solution remains between 5.5 and 6 up to $900 \mathrm{~s}$ (Figure $2 \mathrm{~d}$ ), highlighting a $\mathrm{pH}$ buffering effect of the gelatin.

(a)

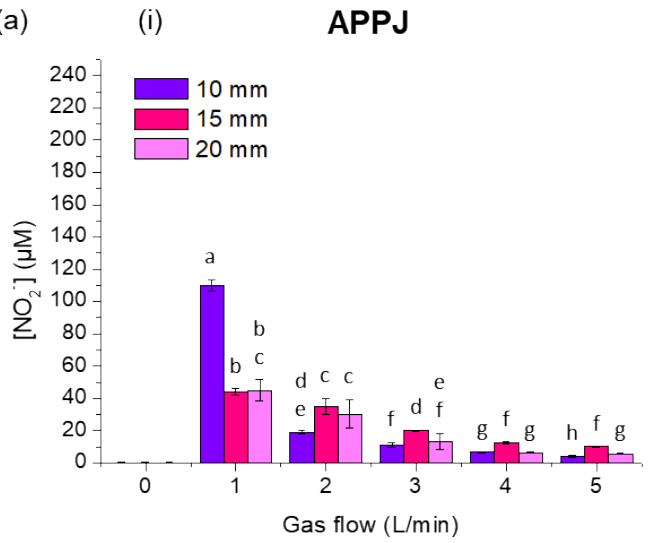

(b)

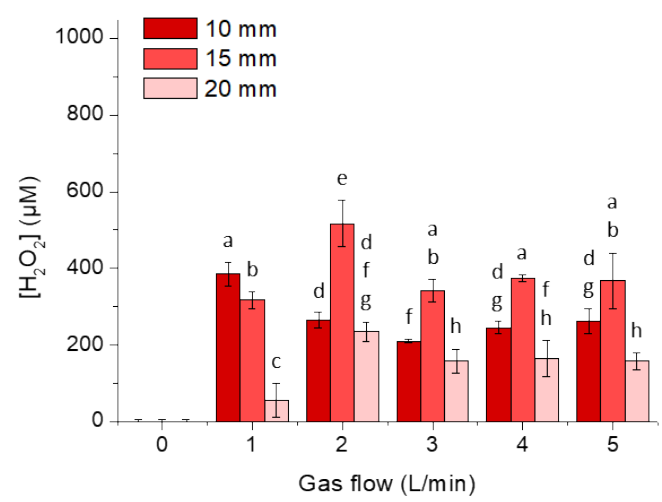

(ii)

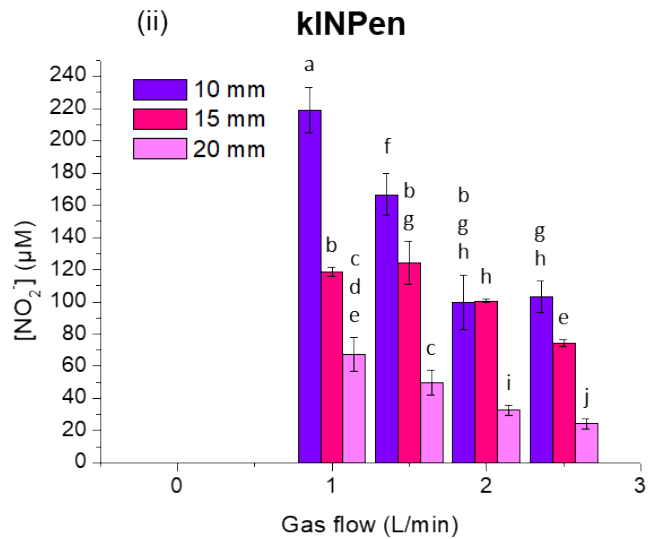

(ii)

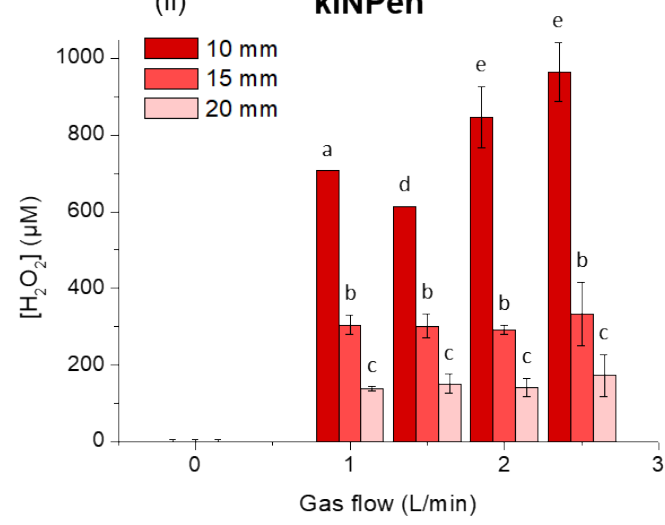

Figure 3. Influence of plasma gas flow rate distance on the concentration of $\mathrm{NO}_{2}^{-}$(a) and $\mathrm{H}_{2} \mathrm{O}_{2}$ (b) from APPJ-and kINPen-treated $2 \%$ gelatin for $90 \mathrm{~s}$. Different letters indicate statistically significant differences (mean sd, $n=3$; p<0.05).

Gas flow rate and distance from the nozzle to the surface of the liquid also play a significant role in the concentration of RONS generated in gelatin (Figure 3a) clearly indicates that higher concentrations of $\mathrm{NO}_{2}{ }^{-}$are generated in gelatin solution under low gas flow rate and short nozzle distance. $\left[\mathrm{NO}_{2}^{-}\right]$is maximized for both plasma devices at $1 \mathrm{~L} / \mathrm{min}$ of gas flow rate and $10 \mathrm{~mm}$ nozzle distance, with concentrations of $112 \mu \mathrm{M}$ and $219 \mu \mathrm{M}$ for APPJ and kINPen, respectively. Under the same working conditions, kINPen generates much more nitrites than APPJ for all conditions studied. In contrast, production of $\mathrm{H}_{2} \mathrm{O}_{2}$ in gelatin (Figure $3 \mathrm{~b}$ ) does not follow the same trend with APPJ with the variation of both nozzle distance and gas flow rates. kINPen displays an increase of $\mathrm{H}_{2} \mathrm{O}_{2}$ production with the decrease of the nozzle distance, as observed for $\mathrm{NO}_{2}^{-}$. In parallel, variation of gas flow does not display variation in the generation of hydrogen peroxides in kINPen-treated gelatin at $15-20 \mathrm{~mm}$ but increases at short distance when increasing gas flow rate.

\subsection{Stability of RONS in gelatin-based hydrogel}


(b)
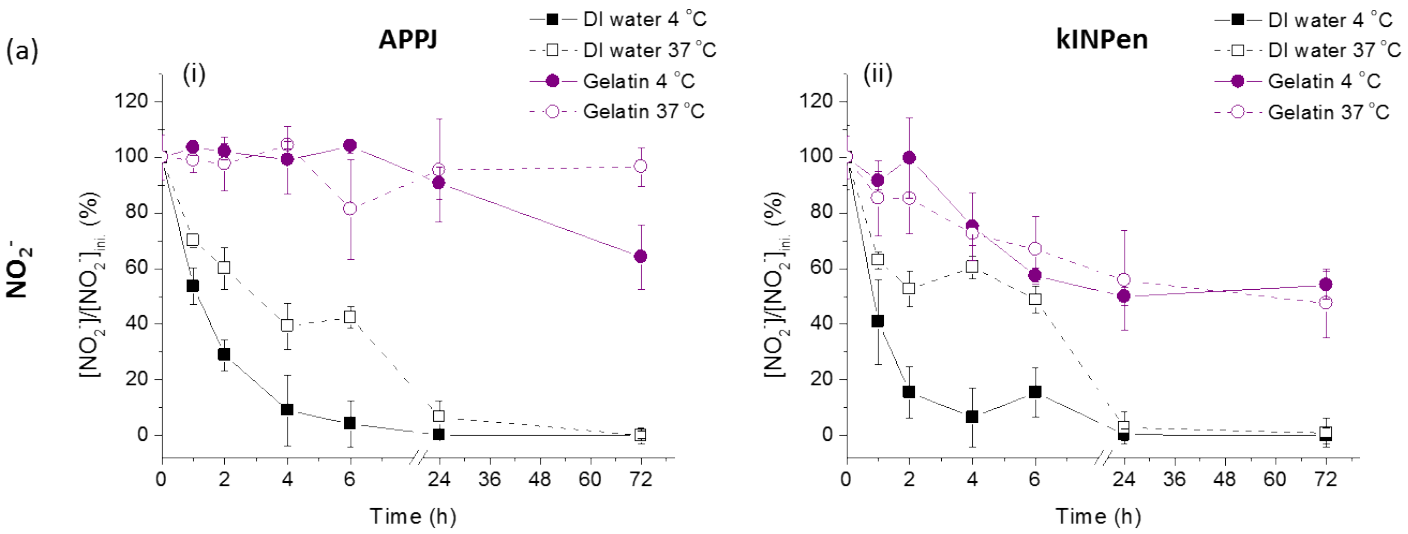

To study the stability of RONS generated in $2 \%$ gelatin solution $\mathrm{NO}_{2}^{-}$and $\mathrm{H}_{2} \mathrm{O}_{2}$ were quantified at different times after plasma treatment, at two storage temperatures: $4{ }^{\circ} \mathrm{C}$ and $37{ }^{\circ} \mathrm{C}$ and compared to DI water as control (Figure 4).
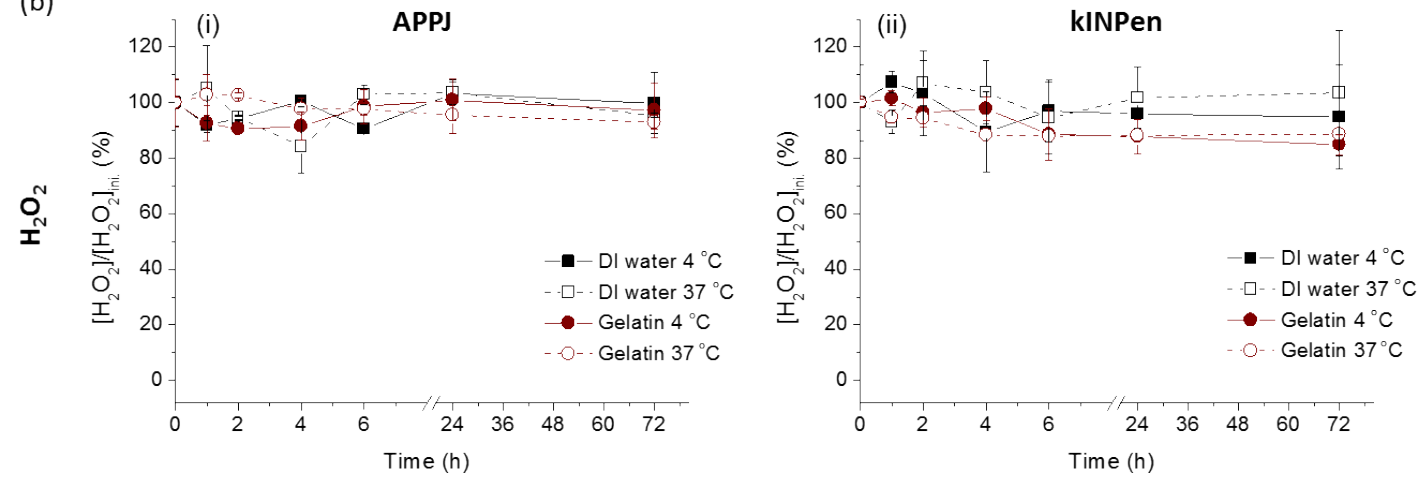

Figure 4: Influence of the storage time and temperature on the ratio of RONS remaining with respect to the initial concentrations of $\mathrm{NO}_{2}^{-}(a)$ and $\mathrm{H}_{2} \mathrm{O}_{2}(b)$ in $2 \%$ gelatin and water generated by APPJ (left side) and kINPen (right side) plasma treatment $(10 \mathrm{~mm}, 1 \mathrm{~L} / \mathrm{min}, 90 \mathrm{~s})$.

For both APPJ- and kINPen-treated water, a quick decrease of nitrites is observed as a function of the storage time, with a quicker disappearance of $\mathrm{NO}_{2}{ }^{-}$at $37{ }^{\circ} \mathrm{C}$ than at $4{ }^{\circ} \mathrm{C}$. No nitrite ions were detected in water after $24 \mathrm{~h}$. This $\mathrm{NO}_{2}$ - decreasing trend is slowed down in plasma-treated gelatin, wherein after 24 hours, around $90 \%$ and $55 \%$ of the initial concentration of $\mathrm{NO}_{2}^{-}$remains in the biomaterial (for APPJ and kINPen, respectively). While almost all $\mathrm{NO}_{2}^{-}$ions react within the first 24 hours in plasma-treated water, hydrogen peroxides are stable, even after hours. The same stability is observed in plasma-treated $2 \%$ gelatin solution, in which $\mathrm{H}_{2} \mathrm{O}_{2}$ concentration remains constant over 72 -hour storage either at $4{ }^{\circ} \mathrm{C}$ or $37{ }^{\circ} \mathrm{C}$. To sum up, gelatin hydrogels improve the stability of plasma-generated RONS, as they allow maintaining constant concentration of $\mathrm{NO}_{2}^{-}$and $\mathrm{H}_{2} \mathrm{O}_{2}$ over time.

\subsection{Release studies of RONS from plasma-treated hydrogels}

The release of $\mathrm{NO}_{2}{ }^{-}$and $\mathrm{H}_{2} \mathrm{O}_{2}$ from the plasma-treated $2 \%$ gelatin to PBS (Figure 5 ) shows a clear dependence of plasma treatment time. Higher release of $\mathrm{NO}_{2}{ }^{-}$and $\mathrm{H}_{2} \mathrm{O}_{2}$ was recorded for longer treatment times, according to the higher initial amount of RONS in the biopolymer. Similarly, the higher amount of RONS generated with kINPen (Figure 2 and Figure 3) result in higher concentrations of nitrites and peroxides released than from the APPJ-treated gelatin solution. 

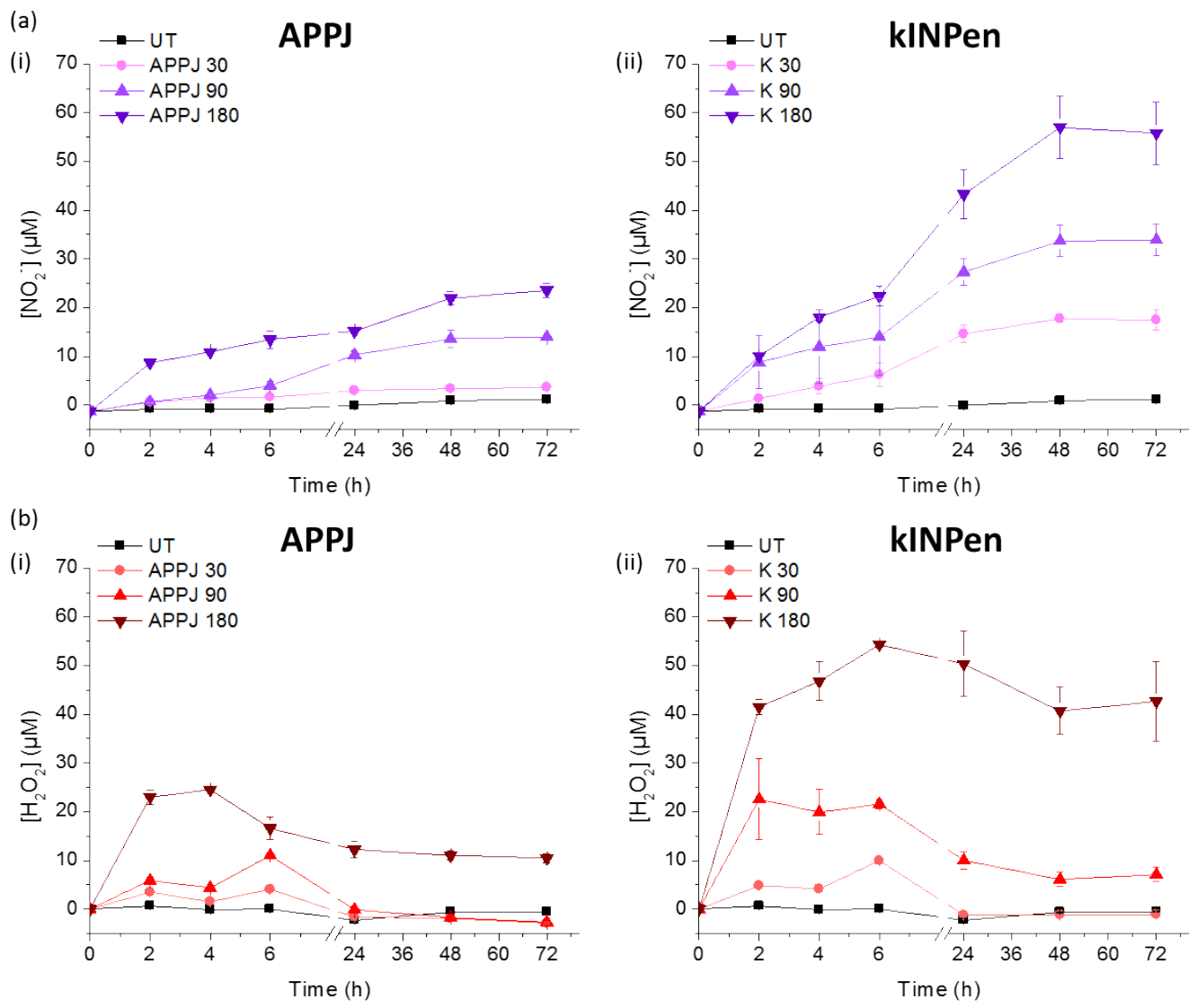

Figure 5. RONS released from APPJ- and kINPen-treated $2 \%$ gelatin solution for 30,90 and $180 \mathrm{~s}$ plasma treatment (10 mm, $1 \mathrm{~L} / \mathrm{min}$ ) to PBS release medium: concentration of $\mathrm{NO}_{2}^{-}$(a) and $\mathrm{H}_{2} \mathrm{O}_{2}$ (b). Untreated gelatin solution was employed as control.

\subsection{In vitro anticancer efficacy}

Sarcoma osteogenic SaOS-2 cells were exposed to APPJ- and kINPen-treated 2\% gelatin to evaluate the impact on cell viability (Figure 6a). As expected, untreated gelatin is completely biocompatible. The plasma-treated gelatin induced bone cancer cell death, with SaOS-2 cell viability decrease by increasing of treatment time, for both plasma devices tested, but being treatment with kINPen more effective on suppressing viability of osteosarcoma cells. Short plasma treatment times (30 s) already reveal important cytotoxic effects on SaOS-2 cells, with cell viability of $71 \%$ for APPJ and $57 \%$ for kINPen after 24 hours. Cell viability diminished to $46 \%$ and $27 \%$ after 24 hours for $180 \mathrm{~s}$ APPJ and kINPen treatment, respectively, and further decreased to $23 \%$ and $12 \%$ after 72 hours. Additionally, while SaOS- 2 cells grow homogenously in the well plate when using untreated gelatin, SaOS-2 are killed preferentially just below the insert with the treated gelatin (lack of cells in this area). The diameter of this area of arrested proliferation increases with plasma treatment time, with absence of living cells for longer plasma treatment times in this area (Supplementary Figure 2). It can be assumed that this corresponds to the area of diffusion of RONS nearer the plasma-treated gelatin solution, confirming that the release of RONS is closely linked with the biological effects observed. 
(a)

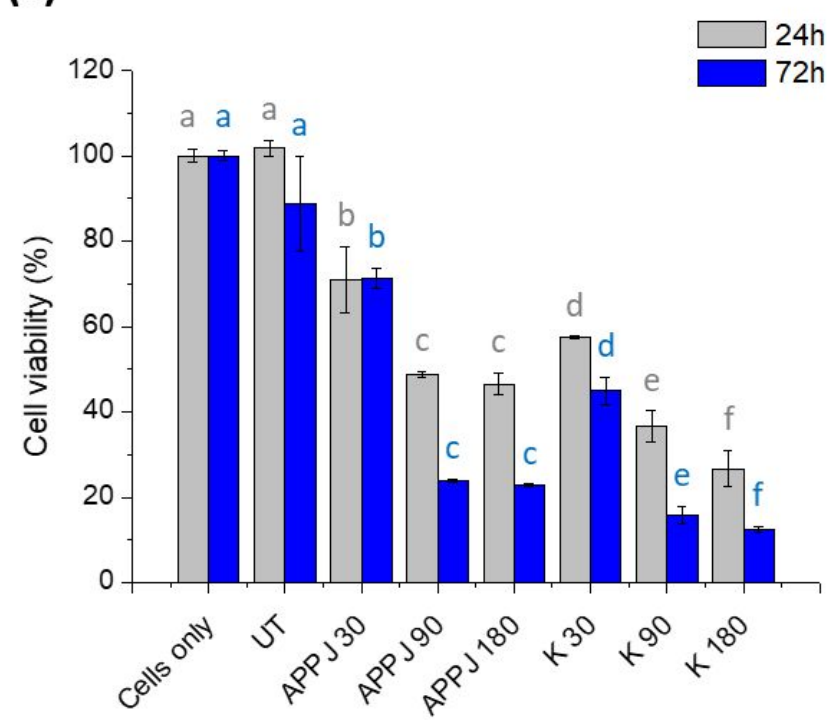

\section{(c)}

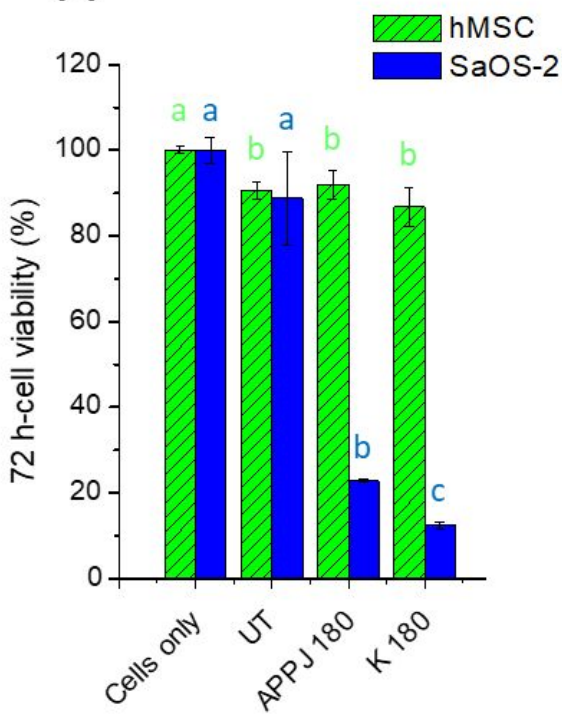

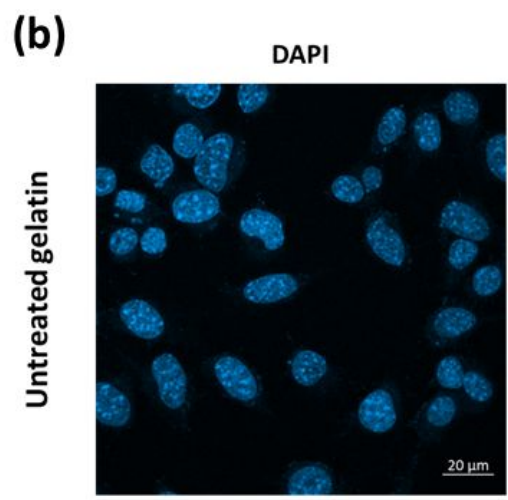

ALEXA FLUOR ${ }^{\circledast} 546$ PHALLOIDIN
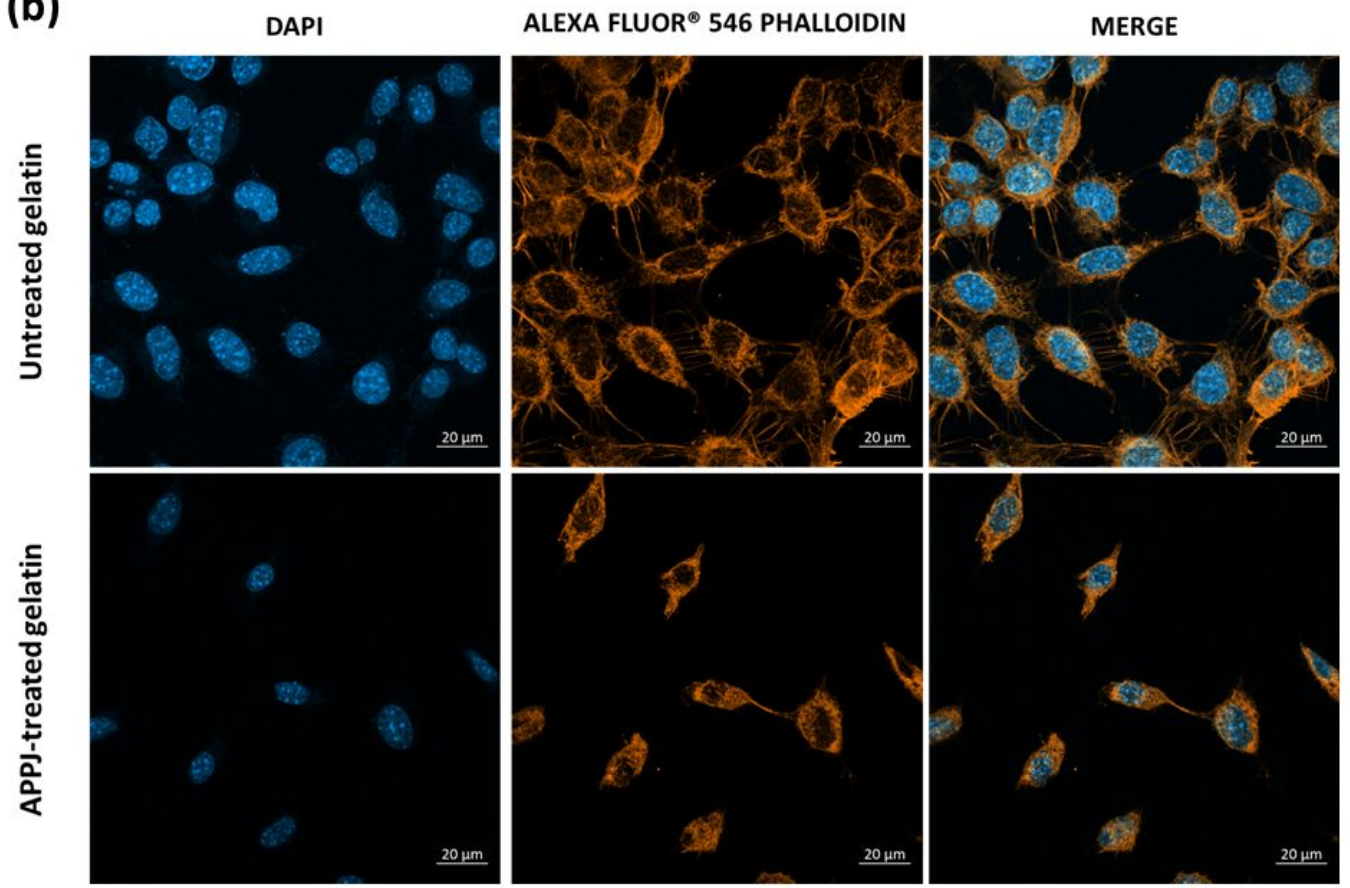

Figure 6. SaOS-2 cell viability after $24 \mathrm{~h}$ and $72 \mathrm{~h}$ exposition to APPJ) and kINPen (K)-treated $2 \%$ gelatin for 30,90 and $180 \mathrm{~s} \mathrm{(a).} \mathrm{Selectivity} \mathrm{of} \mathrm{plasma-treated} \mathrm{gelatin} \mathrm{for} 180 \mathrm{~s}$ using APPJ and kINPen (10 mm, $1 \mathrm{~L} / \mathrm{min})(\mathrm{b})$. Different letters indicate statistically significant differences (mean $s d, n=3 ; p<0.05)$. Confocal microscopy images of SaOS-2 cells placed for 48 hours in presence of untreated gelatin (control) and APPJ-treated gelatin for $90 \mathrm{~s}$ at $1 \mathrm{~L} / \mathrm{min}$ and $10 \mathrm{~mm}$ (c).

Confocal microscopy images (Figure 6b) confirm the previous results; SaOS-2 cells in presence of untreated gelatin display the same morphology than control with cells only. APPJ-treated gelatin induces morphological modifications reflected by a reduction of the expansion or an absence of actin filaments and a reduction of the nuclei size.

Finally, the selectivity of the plasma-treated biomaterial was also tested with hMSC in presence of APPJ and kINPen-treated $2 \%$ gelatin solution for 180 seconds as presented in Figure $6 \mathrm{c}$. While 
presence of untreated gelatin solution with hMSC confirms the biocompatible behavior of the material with 72 -hour cell viability around $91 \%$, the results revealed that plasma treatments of gelatin in the studied conditions have selective effects on cancer cells, maintaining cell viability of healthy cells of $91.9 \pm 3.4 \%$ and $86.8 \pm 4.5 \%$ for 180 s APPJ and kINPen treatment, respectively.

\section{DISCUSSION}

Many studies have shown proof of the anticancer efficacy of plasma-conditioned liquids (PCL) such as physiological saline solutions or culture media9,10,12,14,42-45. As alternative to direct treatment of cancer cells by $\mathrm{CAP}^{46,47}$, that could results more aggressive for healthy cells, the use of PCL presents the advantage of being a minimally-invasive approach with similar in vitro results, including better outcomes especially regarding selectivity. However, one of their limitations is that while they can be delivered locally, the liquids can be quickly washed away by body fluids. Here, the production of RONS by plasma jets was enhanced by using a polymer solution of gelatin (Figure 2) with respect to other saline solutions ${ }^{45}$ or to the first work evaluating a biopolymer solution of alginate ${ }^{16}$. This opens the door to entrapping these RONS in a biopolymer formulation able to act as vehicle for local delivery of RONS for cancer therapy, potentially allowing extended local therapy with the RONS in the tumor site (Figure 4) rather than the conventional plasma-conditioned saline solutions.

Gelatin has been widely used as carrier material for therapeutic cells and drugs due to their excellent biocompatibility and similarities to the extracellular matrix ${ }^{48}$. To meet the stringent requirements of clinical translation of the hydrogels such preparation, application, mechanical properties, etc. a number of modifications of gelatin have also been investigated ${ }^{49}$.

Until now, some works have investigated the diffusion of RONS from plasma jets through gelled (solid) gelatin ${ }^{34,35,50}$ and agarose ${ }^{36,51-54}$, used as tissue models in plasma medicine. These studies showed that plasma treatment of $\mathrm{mm}$ thick gelled gelatin or agarose allow the diffusion of reactive species to a liquid below, as it is thought to happen in vivo, with RONS going through the skin.

Our approach here is novel, as we treat liquid gelatin solutions with cold atmospheric plasma jets to generate RONS within it with the aim to include afterward the plasma-treated biopolymer in the design/formulation of a biomaterial able to act as a delivery system.

Different works ${ }^{55}$ have investigated the production of RONS in water or saline solutions under a broad range of conditions such as volume, treatment time, gas flow and electrode distance ${ }^{2,45,51,56-58}$. To allow easier extrapolation of results, two plasma jets were employed here. Despite that the great variety of configurations in the plasma literature hamper comparative analysis, it is clear that employing a gelatin solution here leads to much higher generation of RONS. Plasma treatment of the $2 \%$ gelatin solution allowed obtaining high concentrations of nitrites and peroxides (Figure $2 \& 3$ ). In water (used as control), the concentrations of $\mathrm{NO}_{2}{ }^{-}$and $\mathrm{H}_{2} \mathrm{O}_{2}$ generated agree with those observed in plasma-conditioned water in previous works ${ }^{55,56}$ using an APPJ in very similar conditions $(20 \mathrm{~mm}, 100 \mu \mathrm{L}$ ) to those employed here. As in our work, the amount of RONS generated increases with plasma treatment time.

Nevertheless, compared to DI water, the amount of RONS generated in $2 \%$ gelatin solution is much higher with any of the two plasma jets investigated here (APPJ or kINPen) (Figure 2). After 3 min of plasma treatment, the amounts of $\mathrm{NO}_{2}{ }^{-}$and $\mathrm{H}_{2} \mathrm{O}_{2}$ generated in gelatin are at least 2 
times higher than in water and can reach up to 4.1 and 7.4 fold for $\mathrm{NO}_{2}^{-}$with APPJ and kINPen, respectively. This enhanced production of RONS in a biopolymer solution than in water or Ringer's saline was also observed in our previous work with alginate solutions ${ }^{59}$. This difference can be explained by the $\mathrm{pH}$ buffering effect of the gelatin solution; while $\mathrm{pH}$ decreased with plasma treatment time in Ringer's saline ${ }^{59}$ or water (Figure $2 \mathrm{~d}$ ), as also reported in other works ${ }^{60-}$ 62 , the $\mathrm{pH}$ remained unaltered in buffered saline such as PBS, in alginate ${ }^{59}$ or here in gelatin solution. In general, different reactions are fostered in acidic media: $\mathrm{NO}_{2}^{-}$reacts with $\mathrm{H}_{2} \mathrm{O}_{2}$ to form peroxynitrites; nitrous acid - one of the major sources of nitrites - decomposes in acidic media) $)^{4,55,63,64}$, among other reactions. Since plasma treatment leads to water acidification, these reactions are promoted in water. However, as gelatin solutions are not displaying acidification (Figure 2d) the reactions consuming peroxides and nitrites are slowed down, leading to higher stability of these RONS. While this hypothesis is clearly a common trend between plasma-treated gelatin solution and plasma-treated alginate solution ${ }^{59}$, the present work demonstrates that the specific polymer employed to produce the solution is also a keypoint regarding the chemical reactivity of the solution with the plasma gas phase. Gelatin solutions are able to generate several-fold higher concentrations of RONS than alginate solutions (i.e. $226.4 \mu \mathrm{M}$ of $\mathrm{NO}_{2}{ }^{-}$and $740 \mu \mathrm{M}$ of $\mathrm{H}_{2} \mathrm{O}_{2}$ were generated in gelatin solution vs. 97.2 $\mu \mathrm{M}$ of $\mathrm{NO}_{2}^{-}$and $111.9 \mu \mathrm{M}$ of $\mathrm{H}_{2} \mathrm{O}_{2}$, in alginate solution under same conditions - $90 \mathrm{~s}$ of kINPen treatment in $200 \mu \mathrm{L}$ of solution at $10 \mathrm{~mm}$ distance and $1 \mathrm{~L} / \mathrm{min}$ Ar flow rate).

Parameters such as plasma gas flow rate or nozzle distance to the liquid surface can be modified to obtain maximum $\mathrm{NO}_{2}{ }^{-}$and $\mathrm{H}_{2} \mathrm{O}_{2}$ concentrations in the liquids treated. Here we observed that $\mathrm{NO}_{2}{ }^{-}$are maximized at short nozzle distance and low gas flow rate, while short distances and high gas flow rates promote higher concentrations of $\mathrm{H}_{2} \mathrm{O}_{2}$ (Figure 3 ). As recorded in a previous work, production of RONS is more efficient under same treatment conditions using kINPen than APPJ $^{59}$ (Figure 2 and Figure 3). One of the reasons supporting this difference between both devices could lie with the thermal effects observed in Figure $1 \mathrm{~b}$ that can affect fluid dynamics and thus generation of RONS. While plasma treatment using kINPen is maintaining the temperature of the polymer solution or the water during plasma-treatment for a same gas flow rate and nozzle distance, the cooling down observed with the samples treated with APPJ may affect the diffusion of the reactive species inside the plasma-treated polymer solution due to its higher viscosity, as gelatin starts jellying at temperatures from $25-28{ }^{\circ} \mathrm{C}$ depending on the concentration and the length of the chain, among others ${ }^{65}$. Lower temperatures revert in a material tending to get a more solid-like behavior, limiting thus the diffusion and generation of RONS inside the polymer network. The difference of behavior in the thermal effects of the samples between APPJ and kINPen most likely arise from the difference of power delivered by both plasma sources. Since the water content in the gas flow is zero in both cases, and thus the contribution of the cooling effect due to evaporation is the same, it can be assumed that the higher power delivered to the plasma discharge by the kINPen (between 0.3 and $3.5 \mathrm{~W}^{66}$ ) with respect to the power delivered by the APPJ ( $0.3 \mathrm{~W}$ measured) is the main reason of the higher counterbalancing in the warming effect presented by the kINPen.

Another important difference between the two sources comes from the type of gas used (He for the APPJ and Ar for the kINPen). Assuming a kinematic viscosity of $1.11 \times 10^{-4} \mathrm{~m}^{2} / \mathrm{s}$ for He and of $1.27 \times 10^{-5} \mathrm{~m}^{2} / \mathrm{s}$ for Ar, for the gas flow rates (1-5 L/min) and the nozzle diameters (APPJ $\varnothing 1.2$ $\mathrm{mm}$, kINPen $\varnothing 1.6 \mathrm{~mm}$ ) adopted in this work the Reynolds number (Re) ranges between 158 and 792 for the APPJ in He and between 1042 and 5200 for the kINPen in Ar. As reported in the literature for a similar jet configuration, a transition from laminar to turbulent flow is expected to occur for Re between 500 and 1000 . Thus, it can be assumed that the APPJ operates mostly 
in a laminar flow regime while the kINPen in a turbulent one. The turbulent vortexes in the kINPen effluent, while limiting the length of the plasma plume (see in Figure 3 the rapid decrease of RONS with increase of the gap distance), can certainly favor the mixing with surrounding air and therefore allow higher production of RONS with respect to the APPJ67,68.

Furthermore, the buffering effect observed here in gelatin solution (Figure $2 b$ ( $i$ and ii)) may also have two important implications: 1 . Cancer cells are known to acidify their environment and, consequently, the interior of the cells themselves is alkalinized. This reverse $\mathrm{pH}$ gradient is associated with tumor proliferation, invasion, metastasis, aggressiveness, and treatment resistance ${ }^{69-75}$, so the fact of having a buffered delivery vehicle for the plasma-generated RONS (instead of the acidic plasma-treated liquids proposed earlier) might be an advantage which should deserve investigation in future works. 2. A more practical advantage of this $\mathrm{pH}$ buffering of gelatin is that it allows the use of the Amplex Red method for detection of $\mathrm{H}_{2} \mathrm{O}_{2}$, since the HRP enzyme employed in this method remains stable in a pH range between 5.0 and 9.0.

In designing biomaterials, the ability to store them is a practical and important asset in views of future commercialization. Interestingly, storage of plasma-treated DI water and gelatin at $4{ }^{\circ} \mathrm{C}$ or physiological conditions $\left(37^{\circ} \mathrm{C}\right)$ revealed that $\mathrm{NO}_{2}{ }^{-}$is more stable in the gelatin solution with respect to water (Figure 4). Whereas almost all the nitrites generated in water disappeared after 24 hours, at least $60 \%$ of the initial concentration of nitrites generated in $2 \%$ gelatin remained in the material after 72 hours. Meanwhile, $\mathrm{H}_{2} \mathrm{O}_{2}$ presents a good stability over time up to 72 hours, either for water or gelatin solution, with at least $84.9 \%$ of the initial concentration of hydrogen peroxides remaining in gelatin solution after 3-day storage. This trend is not only in accordance with a previous work monitoring storage of $\mathrm{H}_{2} \mathrm{O}_{2}$ in water over 21 days ${ }^{60}$, but above all it highlights a better conservation of $\mathrm{H}_{2} \mathrm{O}_{2}$ in water or gelatin than observed in cell culture media, such as $\mathrm{DMEM}^{76}$, where $\mathrm{H}_{2} \mathrm{O}_{2}$ concentrations reported were 10 times lower after 24 hours.

Release kinetics of $\mathrm{NO}_{2}{ }^{-}$and $\mathrm{H}_{2} \mathrm{O}_{2}$ from APPJ- and kINPen-treated gelatin solution to PBS, clearly show that higher amounts of RONS were released from treated gelatin solution for longer treatment times (Figure 5). A sustained release of $\mathrm{NO}_{2}{ }^{-}$can be observed up to 48 hours, whereas $\mathrm{H}_{2} \mathrm{O}_{2}$ shows burst release, with maximum released after 4-6 hours. While $180 \mathrm{~s}$ plasma-treated gelatin solution releases $75 \%$ of $\mathrm{NO}_{2}{ }^{-}$generated with APPJ and $67 \%$ with kINPen after 72 hours, the release percentage of $\mathrm{H}_{2} \mathrm{O}_{2}$ to PBS is much lower, with values of $7 \%$ and $15 \%$, respectively (Supplementary Table 1). However, despite the low release percentage of hydrogen peroxides, the concentrations released allow to observe significant biological effects of SaOS- 2 cells (Figure $5)$.

Osteosarcoma (SaOS-2) cell death was enhanced progressively with plasma-treated gelatin at increasing treatment times (Figure 6a). This can be related to the increasingly higher concentration of RONS produced by plasma jet (Figure 7). This death of cancer cells in a dosedependent manner has been previously associated with biological and molecular mechanisms of necrosis, apoptosis, senescence, and autophagy triggered by CAP treatment ${ }^{77}$. With $\left[\mathrm{H}_{2} \mathrm{O}_{2}\right]$ around $200 \mu \mathrm{M}$ after $30 \mathrm{~s}$ of plasma treatment, cytotoxic effects are already observed with the shortest plasma treatment time. Slightly higher cell cytotoxicity with kINPen than with APPJ can be directly related with the higher amount of RONS generated in the gelatin solution with this plasma jet (Figure 2 and Figure 3). By producing higher amounts of RONS in gelatin than in alginate solutions under the same plasma treatment conditions ${ }^{16}$, an important enhancement of cancer cell cytotoxicity is reached by using gelatin solutions, with 72 -hour cell viability decreasing down to $12 \%$ by using kINPen for $180 \mathrm{~s}$ when alginate solutions presented a SaOS-2 
(a)

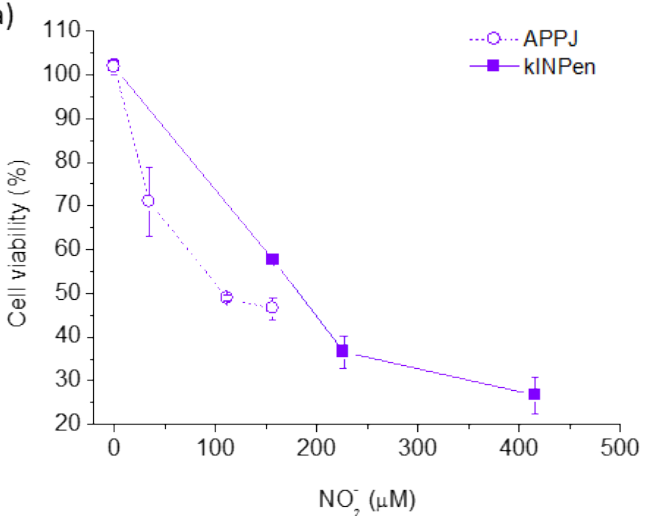

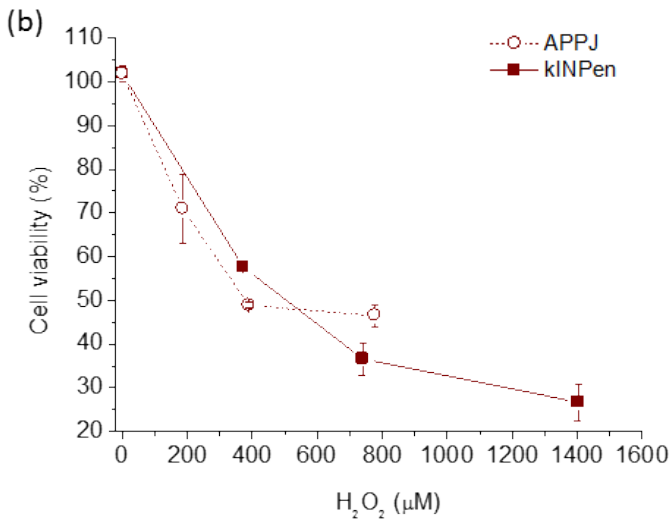

Figure 7: Relationship between $\mathrm{NO}_{2}^{-}(a)$ and $\mathrm{H}_{2} \mathrm{O}_{2}(b)$ generated in $2 \%$ gelatin solutions and the cytotoxicity observed in SaOS-2 cell viability after 24 hours for APPJ and kINPen treatments (10 mm, $1 \mathrm{~L} / \mathrm{min})$.

Morphology and cell density imaged by confocal microscopy (Figure 6b) backup the discussed cellular results for gelatin solution. SaOS-2 osteosarcoma cells in presence of either untreated hydrogels present extended actin filaments and high cell density, accordingly to their suitable biocompatibility (Figure 5a). On the contrary, osteosarcoma cells cultured with plasma-treated gelatin show isolated cells, with fewer adhesion points, smaller nuclei size and more rounded shape, all indicative of the dying fate induced by the plasma-treated biopolymer solutions developed here. Finally, and most importantly, plasma-treated gelatin revealed a selective killing effect on osteosarcoma cells since cell viability of healthy cells (hMSC) is maintained above $90 \%$ after 72 hours (Figure $6 \mathrm{c}$ ). This selective behavior observed with plasma-treated biopolymer solution is in accordance with results obtained in previous works using plasma-conditioned liquids $15,78,79$. As hypothesized for PCL, the mechanism behind this selectivity mainly takes its origin in the difference in basal levels of oxidative stress between healthy and cancer cells lines ${ }^{8,12}$. So, plasma treatment of biopolymer solutions discussed here has several advantages regarding generation and stability of RONS, and above all preserve the biological effects observed with PCL.

\section{CONCLUSIONS}

Herein we designed and characterized a novel vehicle for atmospheric pressure plasmagenerated RONS by comparing two different atmospheric pressure plasma jets. Gelatin solution greatly increases (between 2 and 12-fold) the concentration of RONS produced by cold atmospheric plasma with respect to water. The stability of $\mathrm{NO}_{2}^{-}$generated in gelatin was enhanced and that of $\mathrm{H}_{2} \mathrm{O}_{2}$ was maintained with respect to DI water at least for $72 \mathrm{~h}$. Plasmatreated gelatin solution buffered the $\mathrm{pH}$ decrease observed in water which can be an advantage and partially explains the higher RONS measured. Anticancer effects of plasma-treated gelatin solution are time-dependent in SaOS-2 osteosarcoma cells, being closely related with the increase of RONS generated by plasma at longer treatment times that reverts in a higher release 
of RONS. Plasma-treated gelatin solution revealed a selective lethality on osteosarcoma cells since cell viability of healthy hMSC cells is maintained above $86 \%$ after 72 hours for the longest plasma treatment studied ( $3 \mathrm{~min}$ ), while viability of SaOS-2 decreased to $23 \%$ and $12 \%$ for APPJ and kINPen, respectively. The set of unique features previously described make of gelatin a great candidate for the generation and storage of RONS generated by cold atmospheric plasmas and a relevant material to be used in the design of implantable delivery system, with promising applicability in cancer therapy.

\section{ACKNOWLEDGMENTS}

This project has received funding from the European Research Council (ERC) under the European Union's Horizon 2020 research and innovation programme (grant agreement No 714793). Authors acknowledge the financial support of MINECO for MAT2015-65601-R project (MINECO/FEDER, EU), for the RyC fellowship of CC and of Generalitat de Catalunya for the SGR2017-1165. Support for the research of MPG was received through the ICREA Academia Award for excellence in research, funded by the Generalitat de Catalunya.

\section{REFERENCES}

(1) Bruggeman, P. J.; Kushner, M. J.; Locke, B. R.; Gardeniers, J. G. E.; Graham, W. G.; Graves, D. B.; Hofman-Caris, R. C. H. M.; Maric, D.; Reid, J. P.; Ceriani, E.; Fernandez Rivas, D.; Foster, J. E.; Garrick, S. C.; Gorbanev, Y.; Hamaguchi, S.; Iza, F.; Jablonowski, H.; Klimova, E.; Kolb, J.; Krcma, F.; Lukes, P.; MacHala, Z.; Marinov, I.; Mariotti, D.; Mededovic Thagard, S.; Minakata, D.; Neyts, E. C.; Pawlat, J.; Petrovic, Z. L.; Pflieger, R.; Reuter, S.; Schram, D. C.; Schröter, S.; Shiraiwa, M.; Tarabová, B.; Tsai, P. A.; Verlet, J. R. R.; Von Woedtke, T.; Wilson, K. R.; Yasui, K.; Zvereva, G. Plasma-Liquid Interactions: A Review and Roadmap. Plasma Sources Science and Technology. 2016. https://doi.org/10.1088/0963-0252/25/5/053002.

(2) Chauvin, J.; Judée, F.; Yousfi, M.; Vicendo, P.; Merbahi, N. Analysis of Reactive Oxygen and Nitrogen Species Generated in Three Liquid Media by Low Temperature Helium Plasma Jet. Sci. Rep. 2017. https://doi.org/10.1038/s41598-017-04650-4.

(3) Verlackt, C. C. W.; Van Boxem, W.; Bogaerts, A. Transport and Accumulation of Plasma Generated Species in Aqueous Solution. Phys. Chem. Chem. Phys. 2018, 20 (10), 68456859. https://doi.org/10.1039/C7CP07593F.

(4) Machala, Z.; Tarabova, B.; Hensel, K.; Spetlikova, E.; Sikurova, L.; Lukes, P. Formation of ROS and RNS in Water Electro-Sprayed through Transient Spark Discharge in Air and Their Bactericidal Effects. Plasma Process. Polym. 2013. https://doi.org/10.1002/ppap.201200113.

(5) Yilmazer, A. Cancer Cell Lines Involving Cancer Stem Cell Populations Respond to Oxidative Stress. Biotechnol. reports (Amsterdam, Netherlands) 2017, 17, 24-30. https://doi.org/10.1016/j.btre.2017.11.004.

(6) Reuter, S.; Gupta, S. C.; Chaturvedi, M. M.; Aggarwal, B. B. Oxidative Stress, 
Inflammation, and Cancer: How Are They Linked? Free Radic. Biol. Med. 2010, 49 (11), 1603-1616. https://doi.org/10.1016/j.freeradbiomed.2010.09.006.

(7) Schumacker, P. T. Reactive Oxygen Species in Cancer: A Dance with the Devil. Cancer Cell 2015, 27 (2), 156-157. https://doi.org/10.1016/j.ccell.2015.01.007.

(8) Trachootham, D.; Alexandre, J.; Huang, P. Targeting Cancer Cells by ROS-Mediated Mechanisms: A Radical Therapeutic Approach? Nat. Rev. Drug Discov. 2009, 8, 579.

(9) Van Boxem, W.; Van Der Paal, J.; Gorbanev, Y.; Vanuytsel, S.; Smits, E.; Dewilde, S.; Bogaerts, A. Anti-Cancer Capacity of Plasma-Treated PBS: Effect of Chemical Composition on Cancer Cell Cytotoxicity. Sci. Rep. 2017. https://doi.org/10.1038/s41598-017-16758-8.

(10) Keidar, M. Plasma for Cancer Treatment. Plasma Sources Sci. Technol. 2015, 24 (3), 33001.

(11) Keidar, M.; Shashurin, A.; Volotskova, O.; Ann Stepp, M.; Srinivasan, P.; Sandler, A.; Trink, B. Cold Atmospheric Plasma in Cancer Therapy. Phys. Plasmas 2013. https://doi.org/10.1063/1.4801516.

(12) Yan, D.; Talbot, A.; Nourmohammadi, N.; Sherman, J. H.; Cheng, X.; Keidar, M. Toward Understanding the Selective Anticancer Capacity of Cold Atmospheric Plasma-A Model Based on Aquaporins (Review). Biointerphases 2015, 10 (4), 40801. https://doi.org/10.1116/1.4938020.

(13) Yan, D.; Sherman, J. H.; Keidar, M. Cold Atmospheric Plasma, a Novel Promising AntiCancer Treatment Modality. Oncotarget 2017. https://doi.org/10.18632/oncotarget.13304.

(14) Tanaka, H.; Nakamura, K.; Mizuno, M.; Ishikawa, K.; Takeda, K.; Kajiyama, H.; Utsumi, F.; Kikkawa, F.; Hori, M. Non-Thermal Atmospheric Pressure Plasma Activates Lactate in Ringer's Solution for Anti-Tumor Effects. Sci. Rep. 2016, 6 (1), 36282. https://doi.org/10.1038/srep36282.

(15) Canal, C.; Fontelo, R.; Hamouda, I.; Guillem-Marti, J.; Cvelbar, U.; Ginebra, M. P. PlasmaInduced Selectivity in Bone Cancer Cells Death. Free Radic. Biol. Med. 2017. https://doi.org/10.1016/j.freeradbiomed.2017.05.023.

(16) Labay, C.; Hamouda, I.; Tampieri, F.; Ginebra, M.-P.; Canal, C. Production of Reactive Species in Alginate Hydrogels for Cold Atmospheric Plasma-Based Therapies. Sci. Rep. 2019, 9 (1), 16160. https://doi.org/10.1038/s41598-019-52673-w.

(17) Echave, M. C.; Saenz del Burgo, L.; Pedraz, J. L.; Orive, G. Gelatin as Biomaterial for Tissue Engineering. Curr. Pharm. Des. 2017, 23 (24), 3567-3584. https://doi.org/10.2174/0929867324666170511123101.

(18) Esposito, E.; Cortesi, R.; Nastruzzi, C. Gelatin Microspheres: Influence of Preparation Parameters and Thermal Treatment on Chemico-Physical and Biopharmaceutical Properties. Biomaterials 1996, 17 (20), 2009-2020. https://doi.org/https://doi.org/10.1016/0142-9612(95)00325-8.

(19) Solorio, L.; Zwolinski, C.; Lund, A. W.; Farrell, M. J.; Stegemann, J. P. Gelatin Microspheres Crosslinked with Genipin for Local Delivery of Growth Factors. J. Tissue Eng. Regen. Med. 2010, 4 (7), 514-523. https://doi.org/10.1002/term.267.

(20) Rose, J. C. B. and M. A. and G. E. M. and N. R. W. M. and D. J. P. and A. J. K. and J. W. A. 
and M. P. L. and F. R. A. J. Electrospun Gelatin-Based Scaffolds as a Novel 3D Platform to Study the Function of Contractile Smooth Muscle Cells in Vitro. Biomed. Phys. Eng. Express 2018, 4 (4), 45039.

(21) Poursamar, S. A.; Hatami, J.; Lehner, A. N.; da Silva, C. L.; Ferreira, F. C.; Antunes, A. P. M. Potential Application of Gelatin Scaffolds Prepared through in Situ Gas Foaming in Skin Tissue Engineering. Int. J. Polym. Mater. Polym. Biomater. 2016, 65 (6), 315-322. https://doi.org/10.1080/00914037.2015.1119688.

(22) Tan, J. Y.; Chua, C. K.; Leong, K. F. Indirect Fabrication of Gelatin Scaffolds Using Rapid Prototyping Technology. Virtual Phys. Prototyp. 2010, 5 (1), 45-53. https://doi.org/10.1080/17452751003759144.

(23) Rose, J. B.; Pacelli, S.; Haj, A. J. El; Dua, H. S.; Hopkinson, A.; White, L. J.; Rose, F. R. A. J. Gelatin-Based Materials in Ocular Tissue Engineering. Mater. (Basel, Switzerland) 2014, 7 (4), 3106-3135. https://doi.org/10.3390/ma7043106.

(24) Phull, M. K.; Eydmann, T.; Roxburgh, J.; Sharpe, J. R.; Lawrence-Watt, D. J.; Phillips, G.; Martin, Y. Novel Macro-Microporous Gelatin Scaffold Fabricated by Particulate Leaching for Soft Tissue Reconstruction with Adipose-Derived Stem Cells. J. Mater. Sci. Mater. Med. 2013, 24 (2), 461-467. https://doi.org/10.1007/s10856-012-4806-0.

(25) Aliakbarshirazi, S.; Talebian, A. Electrospun Gelatin Nanofibrous Scaffolds for Cartilage Tissue Engineering. Mater. Today Proc. 2017, 4 (7, Part 1), 7059-7064. https://doi.org/https://doi.org/10.1016/j.matpr.2017.07.038.

(26) Aldana, A. A.; Abraham, G. A. Current Advances in Electrospun Gelatin-Based Scaffolds for Tissue Engineering Applications. Int. J. Pharm. 2017, 523 (2), 441-453. https://doi.org/10.1016/j.ijpharm.2016.09.044.

(27) Dias, J. R.; Baptista-Silva, S.; Oliveira, C. M. T. de; Sousa, A.; Oliveira, A. L.; Bártolo, P. J.; Granja, P. L. In Situ Crosslinked Electrospun Gelatin Nanofibers for Skin Regeneration. Eur. Polym. J. 2017, 95, 161-173. https://doi.org/https://doi.org/10.1016/j.eurpolymj.2017.08.015.

(28) Fassina, L.; Saino, E.; Visai, L.; Avanzini, M. A.; Cusella De Angelis, M. G.; Benazzo, F.; Van Vlierberghe, S.; Dubruel, P.; Magenes, G. Use of a Gelatin Cryogel as Biomaterial Scaffold in the Differentiation Process of Human Bone Marrow Stromal Cells. Conf. Proc. ... Annu. Int. Conf. IEEE Eng. Med. Biol. Soc. IEEE Eng. Med. Biol. Soc. Annu. Conf. 2010, 2010, 247-250. https://doi.org/10.1109/IEMBS.2010.5627475.

(29) Zhang, Y.; Ouyang, H.; Lim, C. T.; Ramakrishna, S.; Huang, Z.-M. Electrospinning of Gelatin Fibers and Gelatin/PCL Composite Fibrous Scaffolds. J. Biomed. Mater. Res. B. Appl. Biomater. 2005, 72 (1), 156-165. https://doi.org/10.1002/jbm.b.30128.

(30) Raina, D. B.; Larsson, D.; Mrkonjic, F.; Isaksson, H.; Kumar, A.; Lidgren, L.; Tägil, M. Gelatin- Hydroxyapatite- Calcium Sulphate Based Biomaterial for Long Term Sustained Delivery of Bone Morphogenic Protein-2 and Zoledronic Acid for Increased Bone Formation: In-Vitro and in-Vivo Carrier Properties. J. Control. Release 2018, 272, 83-96. https://doi.org/https://doi.org/10.1016/j.jconrel.2018.01.006.

(31) Kessler, L.; Gehrke, S.; Winnefeld, M.; Huber, B.; Hoch, E.; Walter, T.; Wyrwa, R.; Schnabelrauch, M.; Schmidt, M.; Kückelhaus, M.; Lehnhardt, M.; Hirsch, T.; Jacobsen, F. Methacrylated Gelatin/Hyaluronan-Based Hydrogels for Soft Tissue Engineering. J. Tissue Eng. 2017, 8, $2041731417744157-2041731417744157$. https://doi.org/10.1177/2041731417744157. 
(32) Gattazzo, F.; De Maria, C.; Rimessi, A.; Dona, S.; Braghetta, P.; Pinton, P.; Vozzi, G.; Bonaldo, P. Gelatin-Genipin-Based Biomaterials for Skeletal Muscle Tissue Engineering. J. Biomed. Mater. Res. B. Appl. Biomater. 2018, 106 (8), 2763-2777. https://doi.org/10.1002/jbm.b.34057.

(33) Szili, S. E. M. and A. T. A. J. and S. A. A.-B. and R. D. S. and S.-H. H. and N. T. T. and J.-S. O. and J. W. B. and E. J. Studying the Cytolytic Activity of Gas Plasma with Self-Signalling Phospholipid Vesicles Dispersed within a Gelatin Matrix. J. Phys. D. Appl. Phys. 2013, 46 (18), 185401.

(34) Short, E. J. S. and J. W. B. and R. D. A 'Tissue Model' to Study the Plasma Delivery of Reactive Oxygen Species. J. Phys. D. Appl. Phys. 2014, 47 (15), 152002.

(35) Gaur, N.; Szili, E. J.; Oh, J.-S.; Hong, S.-H.; Michelmore, A.; Graves, D. B.; Hatta, A.; Short, R. D. Combined Effect of Protein and Oxygen on Reactive Oxygen and Nitrogen Species in the Plasma Treatment of Tissue. Appl. Phys. Lett. 2015, 107 (10), 103703. https://doi.org/10.1063/1.4930874.

(36) Short, E. J. S. and J.-S. O. and S.-H. H. and A. H. and R. D. Probing the Transport of Plasma-Generated RONS in an Agarose Target as Surrogate for Real Tissue: Dependency on Time, Distance and Material Composition. J. Phys. D. Appl. Phys. 2015, 48 (20), 202001.

(37) Szili, E. J.; Hong, S.-H.; Short, R. D. On the Effect of Serum on the Transport of Reactive Oxygen Species across Phospholipid Membranes. Biointerphases 2015, 10 (2), 29511. https://doi.org/10.1116/1.4918765.

(38) Zaplotnik, R.; Bišćan, M.; Kregar, Z.; Cvelbar, U.; Mozetič, M.; Milošević, S. Influence of a Sample Surface on Single Electrode Atmospheric Plasma Jet Parameters. Spectrochim. Acta Part B At. Spectrosc. 2015, 103-104, 124-130. https://doi.org/https://doi.org/10.1016/j.sab.2014.12.004.

(39) Reuter, S.; von Woedtke, T.; Weltmann, K.-D. The KINPen-a Review on Physics and Chemistry of the Atmospheric Pressure Plasma Jet and Its Applications. J. Phys. D. Appl. Phys. 2018, 51 (23), 233001.

(40) Guevara, I.; Iwanejko, J.; Dembinska-Kiec, A.; Pankiewicz, J.; Wanat, A.; Anna, P.; Golabek, I.; Bartus, S.; Malczewska-Malec, M.; Szczudlik, A. Determination of Nitrite/Nitrate in Human Biological Material by the Simple Griess Reaction. Clin. Chim. Acta. 1998, 274 (2), 177-188.

(41) Giustarini, D.; Rossi, R.; Milzani, A.; Dalle-Donne, I. Nitrite and Nitrate Measurement by Griess Reagent in Human Plasma: Evaluation of Interferences and Standardization. Methods Enzymol. 2008, 440, 361-380. https://doi.org/10.1016/S0076-6879(07)008233.

(42) Kaushik, N. K.; Ghimire, B.; Li, Y.; Adhikari, M.; Veerana, M.; Kaushik, N.; Jha, N.; Adhikari, B.; Lee, S.-J.; Masur, K.; von Woedtke, T.; Weltmann, K.-D.; Choi, E. H. Biological and Medical Applications of Plasma-Activated Media, Water and Solutions. Biol. Chem. 2018, 400 (1), 39-62. https://doi.org/10.1515/hsz-2018-0226.

(43) Azzariti, A.; lacobazzi, R. M.; Di Fonte, R.; Porcelli, L.; Gristina, R.; Favia, P.; Fracassi, F.; Trizio, I.; Silvestris, N.; Guida, G.; Tommasi, S.; Sardella, E. Plasma-Activated Medium Triggers Cell Death and the Presentation of Immune Activating Danger Signals in Melanoma and Pancreatic Cancer Cells. Sci. Rep. 2019, 9 (1), 4099. https://doi.org/10.1038/s41598-019-40637-z. 
(44) Liedtke, K. R.; Bekeschus, S.; Kaeding, A.; Hackbarth, C.; Kuehn, J.-P.; Heidecke, C.-D.; von Bernstorff, W.; von Woedtke, T.; Partecke, L. I. Non-Thermal Plasma-Treated Solution Demonstrates Antitumor Activity against Pancreatic Cancer Cells in Vitro and in Vivo. Sci. Rep. 2017, 7 (1), 8319. https://doi.org/10.1038/s41598-017-08560-3.

(45) Mateu-Sanz, M.; Tornín, J.; Brulin, B.; Khlyustova, A.; Ginebra, M.-P.; Layrolle, P.; Canal, C. Cold Plasma-Treated Ringer's Saline: A Weapon to Target Osteosarcoma. Cancers (Basel). 2020, 12 (1), 227. https://doi.org/10.3390/cancers12010227.

(46) Yan, D.; Wang, Q.; Adhikari, M.; Malyavko, A.; Lin, L.; Zolotukhin, D.; Yao, X.; Kirschner, M.; Sherman, J. H.; Keidar, M. A Physically Triggered Cell Death via Transbarrier Cold Atmospheric Plasma Cancer Treatment. ACS Appl. Mater. Interfaces 2020. https://doi.org/10.1021/acsami.0c06500.

(47) Gjika, E.; Pal-Ghosh, S.; Tang, A.; Kirschner, M.; Tadvalkar, G.; Canady, J.; Stepp, M. A.; Keidar, M. Adaptation of Operational Parameters of Cold Atmospheric Plasma for in Vitro Treatment of Cancer Cells. ACS Appl. Mater. Interfaces 2018, 10 (11), 9269-9279. https://doi.org/10.1021/acsami.7b18653.

(48) Xu, J.; Feng, Q.; Lin, S.; Yuan, W.; Li, R.; Li, J.; Wei, K.; Chen, X.; Zhang, K.; Yang, Y.; Wu, T.; Wang, B.; Zhu, M.; Guo, R.; Li, G.; Bian, L. Injectable Stem Cell-Laden Supramolecular Hydrogels Enhance in Situ Osteochondral Regeneration via the Sustained Co-Delivery of Hydrophilic and Hydrophobic Chondrogenic Molecules. Biomaterials 2019. https://doi.org/https://doi.org/10.1016/j.biomaterials.2019.04.031.

(49) Feng, Q.; Wei, K.; Lin, S.; Xu, Z.; Sun, Y.; Shi, P.; Li, G.; Bian, L. Mechanically Resilient, Injectable, and Bioadhesive Supramolecular Gelatin Hydrogels Crosslinked by Weak Host-Guest Interactions Assist Cell Infiltration and in Situ Tissue Regeneration.

Biomaterials 2016, 101, 217-228.

https://doi.org/https://doi.org/10.1016/j.biomaterials.2016.05.043.

(50) Kong, T. H. and D. L. and H. X. and Z. liu and D. X. and D. L. and Q. L. and M. R. and M. G. A 'Tissue Model' to Study the Barrier Effects of Living Tissues on the Reactive Species Generated by Surface Air Discharge. J. Phys. D. Appl. Phys. 2016, 49 (20), 205204.

(51) Oh, J.-S.; Szili, E. J.; Ito, S.; Hong, S.-H.; Gaur, N.; Furuta, H.; Short, R. D.; Hatta, A. Slow Molecular Transport of Plasma-Generated Reactive Oxygen and Nitrogen Species and O2 through Agarose as a Surrogate for Tissue. Plasma Med. 2015. https://doi.org/10.1615/PlasmaMed.2016015740.

(52) Oh, J.-S.; Szili, E. J.; Gaur, N.; Hong, S.-H.; Furuta, H.; Kurita, H.; Mizuno, A.; Hatta, A.; Short, R. D. How to Assess the Plasma Delivery of RONS into Tissue Fluid and Tissue. J. Phys. D. Appl. Phys. 2016, 49 (30), 304005. https://doi.org/10.1088/0022$3727 / 49 / 30 / 304005$.

(53) Kawasaki, T.; Sato, A.; Kusumegi, S.; Kudo, A.; Sakanoshita, T.; Tsurumaru, T.; Uchida, G.; Koga, K.; Shiratani, M. Two-Dimensional Concentration Distribution of Reactive Oxygen Species Transported through a Tissue Phantom by Atmospheric-Pressure Plasma-Jet Irradiation. Appl. Phys. Express 2016, 9 (7), 76202. https://doi.org/10.7567/apex.9.076202.

(54) Oh, J.-S.; Szili, E. J.; Gaur, N.; Hong, S.-H.; Furuta, H.; Short, R. D.; Hatta, A. In-Situ UV Absorption Spectroscopy for Monitoring Transport of Plasma Reactive Species through Agarose as Surrogate for Tissue. J. Photopolym. Sci. Technol. 2015, 28 (3), 439-444. https://doi.org/10.2494/photopolymer.28.439. 
(55) Khlyustova, A.; Labay, C.; Machala, Z.; Ginebra, M.-P.; Canal, C. Important Parameters in Plasma Jets for the Production of RONS in Liquids for Plasma Medicine: A Brief Review. Front. Chem. Sci. Eng. 2019. https://doi.org/10.1007/s11705-019-1801-8.

(56) Chen, Z.; Simonyan, H.; Cheng, X.; Gjika, E.; Lin, L.; Canady, J.; Sherman, J. H.; Young, C.; Keidar, M. A Novel Micro Cold Atmospheric Plasma Device for Glioblastoma Both in Vitro and in Vivo. Cancers (Basel). 2017. https://doi.org/10.3390/cancers9060061.

(57) Attri, P.; Yusupov, M.; Park, J. H.; Lingamdinne, L. P.; Koduru, J. R.; Shiratani, M.; Choi, E. H.; Bogaerts, A. Mechanism and Comparison of Needle-Type Non-Thermal Direct and Indirect Atmospheric Pressure Plasma Jets on the Degradation of Dyes. Sci. Rep. 2016. https://doi.org/10.1038/srep34419.

(58) Oh, J.-S.; Szili, E. J.; Ogawa, K.; Short, R. D.; Ito, M.; Furuta, H.; Hatta, A. UV-Vis Spectroscopy Study of Plasma-Activated Water: Dependence of the Chemical Composition on Plasma Exposure Time and Treatment Distance. Jpn. J. Appl. Phys. 2018, 57 (1), 0102B9. https://doi.org/10.7567/JJAP.57.0102B9.

(59) Labay, Cédric; Hamouda, Inès; Tampieri, Francesco; Ginebra, Maria-Pau; Canal, C. Production of Reactive Species in Alginate Hydrogels for Cold Atmospheric PlasmaBased Therapies. Sci. Rep. 2019.

(60) Vlad, I.-E.; Anghel, S. D. Time Stability of Water Activated by Different On-Liquid Atmospheric Pressure Plasmas. J. Electrostat. 2017, 87, 284-292. https://doi.org/https://doi.org/10.1016/j.elstat.2017.06.002.

(61) Zhou, R.; Zhou, R.; Prasad, K.; Fang, Z.; Speight, R.; Bazaka, K.; Ostrikov, K. (Ken). Cold Atmospheric Plasma Activated Water as a Prospective Disinfectant: The Crucial Role of Peroxynitrite. Green Chem. 2018, 20 (23), 5276-5284. https://doi.org/10.1039/C8GC02800A.

(62) Abuzairi, T.; Ramadhanty, S.; Puspohadiningrum, D. F.; Ratnasari, A.; Poespawati, N. R.; Purnamaningsih, R. W. Investigation on Physicochemical Properties of Plasma-Activated Water for the Application of Medical Device Sterilization. AIP Conf. Proc. 2018, 1933 (1), 40017. https://doi.org/10.1063/1.5023987.

(63) Bosi, F. J.; Tampieri, F.; Marotta, E.; Bertani, R.; Pavarin, D.; Paradisi, C. Characterization and Comparative Evaluation of Two Atmospheric Plasma Sources for Water Treatment. Plasma Process. Polym. 2018, 15 (3), 1700130. https://doi.org/10.1002/ppap.201700130.

(64) Clupek, P. L. and E. D. and I. S. and M. Aqueous-Phase Chemistry and Bactericidal Effects from an Air Discharge Plasma in Contact with Water: Evidence for the Formation of Peroxynitrite through a Pseudo-Second-Order Post-Discharge Reaction of H 202 and HNO 2. Plasma Sources Sci. Technol. 2014, 23 (1), 15019.

(65) Tosh, S. M.; Marangoni, A. G. Determination of the Maximum Gelation Temperature in Gelatin Gels. Appl. Phys. Lett. 2004, 84 (21), 4242-4244.

https://doi.org/10.1063/1.1756210.

(66) Reuter, S.; von Woedtke, T.; Weltmann, K.-D. The KINPen-a Review on Physics and Chemistry of the Atmospheric Pressure Plasma Jet and Its Applications. J. Phys. D. Appl. Phys. 2018, 51 (23), 233001.

(67) Stancampiano, A.; Simoncelli, E.; Boselli, M.; Colombo, V.; Gherardi, M. Experimental Investigation on the Interaction of a Nanopulsed Plasma Jet with a Liquid Target. 
Plasma Sources Sci. Technol. 2018, 27 (12), 125002. https://doi.org/10.1088/13616595/aae9d0.

(68) Ungate, C.; Harleman, D.; Jirka, G. Stability and Mixing of Submerged Turbulent Jets at Low Reynolds Numbers. MIT Dep Civ Eng Ralph M, Parsons Lab Water Resour Hydrodyn Rep 1975.

(69) Persi, E.; Duran-Frigola, M.; Damaghi, M.; Roush, W. R.; Aloy, P.; Cleveland, J. L.; Gillies, R. J.; Ruppin, E. Systems Analysis of Intracellular PH Vulnerabilities for Cancer Therapy. Nat. Commun. 2018, 9 (1), 2997. https://doi.org/10.1038/s41467-018-05261-x.

(70) Schulze, A.; Harris, A. L. How Cancer Metabolism Is Tuned for Proliferation and Vulnerable to Disruption. Nature 2012, 491, 364.

(71) Webb, B. A.; Chimenti, M.; Jacobson, M. P.; Barber, D. L. Dysregulated PH: A Perfect Storm for Cancer Progression. Nat. Rev. Cancer 2011, 11, 671.

(72) Gatenby, R. A.; Gillies, R. J. Why Do Cancers Have High Aerobic Glycolysis? Nat. Rev. Cancer 2004, 4 (11), 891-899. https://doi.org/10.1038/nrc1478.

(73) Gatenby, R. A.; Gawlinski, E. T.; Gmitro, A. F.; Kaylor, B.; Gillies, R. J. Acid-Mediated Tumor Invasion: A Multidisciplinary Study. Cancer Res. 2006, 66 (10), 5216 LP - 5223. https://doi.org/10.1158/0008-5472.CAN-05-4193.

(74) Robey, I. F.; Baggett, B. K.; Kirkpatrick, N. D.; Roe, D. J.; Dosescu, J.; Sloane, B. F.; Hashim, A. I.; Morse, D. L.; Raghunand, N.; Gatenby, R. A.; Gillies, R. J. Bicarbonate Increases Tumor PH and Inhibits Spontaneous Metastases. Cancer Res. 2009, 69 (6), 2260 LP - 2268. https://doi.org/10.1158/0008-5472.CAN-07-5575.

(75) McCarty, M. F.; Whitaker, J. Manipulating Tumor Acidification as a Cancer Treatment Strategy. Altern. Med. Rev. 2010, 15 (3), 264-272.

(76) Hoentsch, M.; Bussiahn, R.; Rebl, H.; Bergemann, C.; Eggert, M.; Frank, M.; von Woedtke, T.; Nebe, B. Persistent Effectivity of Gas Plasma-Treated, Long Time-Stored Liquid on Epithelial Cell Adhesion Capacity and Membrane Morphology. PLoS One 2014, 9 (8), e104559.

(77) Semmler, M. L.; Bekeschus, S.; Schäfer, M.; Bernhardt, T.; Fischer, T.; Witzke, K.; Seebauer, C.; Rebl, H.; Grambow, E.; Vollmar, B.; Nebe, J. B.; Metelmann, H.-R.; Woedtke, T. von; Emmert, S.; Boeckmann, L. Molecular Mechanisms of the Efficacy of Cold Atmospheric Pressure Plasma (CAP) in Cancer Treatment. Cancers (Basel). 2020, 12 (2), 269. https://doi.org/10.3390/cancers12020269.

(78) Laroussi, M. Effects of PAM on Select Normal and Cancerous Epithelial Cells. Plasma Res. Express 2019, 1 (2), 25010. https://doi.org/10.1088/2516-1067/ab1b8a.

(79) Xiang, L.; Xu, X.; Zhang, S.; Cai, D.; Dai, X. Cold Atmospheric Plasma Conveys Selectivity on Triple Negative Breast Cancer Cells Both in Vitro and in Vivo. Free Radic. Biol. Med. 2018, 124, 205-213. https://doi.org/10.1016/j.freeradbiomed.2018.06.001. 
All authors have approved the submitted version;

All authors have agreed both to be personally accountable for the author's own contributions and to ensure that questions related to the accuracy or integrity of any part of the work, even ones in which the author was not personally involved, are appropriately investigated, resolved, and the resolution documented in the literature.

\section{Declaration of interests}

Following the competing interests statement guidelines of the publication, the authors declare no competing interests. 